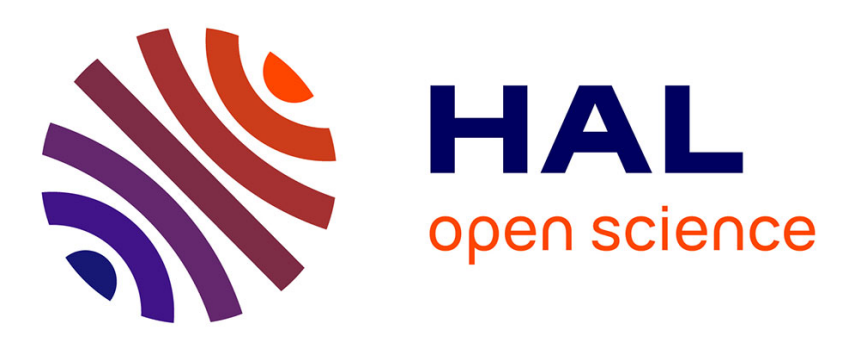

\title{
Experimental and numerical investigation on carbonitrided steel characterization with spherical indentation
}

\author{
Charbel Moussa, Olivier Bartier, Gerard Mauvoisin, Xavier Hernot, \\ Jean-Marc Collin, Guillaume Delattre
}

\section{To cite this version:}

Charbel Moussa, Olivier Bartier, Gerard Mauvoisin, Xavier Hernot, Jean-Marc Collin, et al.. Experimental and numerical investigation on carbonitrided steel characterization with spherical indentation. Surface and Coatings Technology, 2014, 258, pp.782-789. 10.1016/j.surfcoat.2014.07.080 . hal-01072549

\section{HAL Id: hal-01072549 \\ https://hal.science/hal-01072549}

Submitted on 8 Oct 2014

HAL is a multi-disciplinary open access archive for the deposit and dissemination of scientific research documents, whether they are published or not. The documents may come from teaching and research institutions in France or abroad, or from public or private research centers.
L'archive ouverte pluridisciplinaire HAL, est destinée au dépôt et à la diffusion de documents scientifiques de niveau recherche, publiés ou non, émanant des établissements d'enseignement et de recherche français ou étrangers, des laboratoires publics ou privés. 


\title{
Experimental and numerical investigation on carbonitrided steel characterization with spherical indentation
}

\author{
Charbel Moussa $^{\mathrm{a}^{*},}$, Olivier Bartier ${ }^{\mathrm{a}}$, Gérard Mauvoisin ${ }^{\mathrm{a}}$, Xavier Hernot ${ }^{\mathrm{a}}$, Jean-Marc Collin ${ }^{\mathrm{a}, \mathrm{b}}$, \\ Guillaume Delattre ${ }^{\mathrm{c}}$ \\ ${ }^{a}$ LGCGM, EA 3913, Université de Rennes 1 - INSA de Rennes, 20 Avenue des Buttes de Coësmes, 35708 \\ Rennes Cedex 7, France \\ ${ }^{\mathrm{b}}$ Université de Nantes, 1 quai de Tourville, BP 13522, 44035 Nantes Cedex 1, France \\ ${ }^{\mathrm{c}}$ FAURECIA Automotive seating, Le pont de Vère, 61100 Caligny, France
}

\author{
*Corresponding author \\ mail adress : charbel.mouss@gmail.com \\ charbel.moussa@univ-rennes1.fr \\ tel : +33223238909
}

\begin{abstract}
This study investigates the mechanical behaviour of a carbonitrided steel, plastically graded material, during a spherical indentation test. We demonstrate that the behaviour of a carbonitrided steel can be simulated accurately with a seven layer sample, including the surface, five intermediate layers and the substrate. Moreover, for engineering design simulations which require a lot of calculation time, using three layers provides a good compromise for accuracy.

A complete experimental procedure involving seven successive identifications with inverse analysis gave the same results as a simpler procedure proposed in a previous paper. It is shown that the assumption of a linear variation of the properties in the intermediate layers between surface and substrate is valid. This is the first time that an instrumented roller indentation test has demonstrated the reliability of the proposed method for the mechanical characterization of carbonitrided steels with spherical indentation.
\end{abstract}

\section{Introduction}

Surface heat treatment such as carbonitriding is often used to combine high surface strength and high core toughness of mechanical parts submitted to wear and fatigue. The carbonitrided steels present a variation in hardness with depth from the surface while the elastic properties are not affected by the treatment and are constants with depth [1-4]. For these reasons they can be called plastically graded materials (PGM).

The use of classic tensile tests on that kind of material does not provide an accurate prediction of the variation of the mechanical properties with depth. Indeed, carbonitriding alters only the top layers of the material, which have a very small volume compared to the volume of the whole part. However, mechanical characterization of PGM is an important challenge for engineering industries. A precise knowledge of the mechanical properties is necessary to obtain efficient finite element (FE) results for the design of engineering parts. Considering this problem, instrumented indentation tests have a great potential for the characterization of PGM due to the small volume of material tested.

It has been demonstrated that the indentation test can provide an accurate prediction of the mechanical behaviour of homogenous materials [5-14]. This test does not directly provide the stress-strain curve $\sigma(\varepsilon)$ of the tested sample but an indentation load-depth curve $F(h)$ from which the parameters of the material's hardening law can be determined. The simpler and quite accurate elastic-plastic law for metals is the piecewise linear/Hollomon's power-law $[15,16]$ given by equation (1): 
$\left\{\begin{array}{l}\sigma=E \varepsilon ; \sigma<\sigma_{y} \\ \sigma=\sigma_{y}^{1-n} E^{n} \varepsilon^{n} ; \sigma \geq \sigma_{y}\end{array}\right.$

where $E$ is the Young's modulus, $\sigma_{y}$ the yield stress and $n$ the strain hardening exponent.

The determination of the mechanical parameters of Eq. (1) from the indentation curve can be undertaken using multiple approaches. The first one is often called "reverse analysis" and is based on the minimization of the least squares deviation between indentation experiments and models, linking the indentation load, the displacement and the hardening law parameters, previously determined by numerical simulations [5-10]. The second approach is called "inverse analysis" where the minimization is directly carried out between experiments and FE simulations. Several authors [11-13] suggested applying the inverse analysis approach on indentation experiments in order to determine some mechanical properties. Using "reverse analysis" with predetermined models of indentation is convenient because it does not require additional FE simulations and thus is a quick method. However, the proposed models of indentation data are limited to a great number of conditions, such as indenter shape, mechanical behavior of the tested sample, homogeneity of the sample, friction conditions, etc ... For this reason "inverse analysis" is a good alternative method when the conditions of the test are not taken into account in the proposed models of indentation, as is done for more complex behavior laws [12,13]. The third approach [14] consists of building up a database of FE simulation curves and to calculate the error between the experimental curve and the curves of the database. The definition of the equation that describes the distribution of the error allows for the determination of the parameters of the hardening law that represents the material.

A complete overview of the theory realized by Moussa et al. [13] has shown that, compared to homogenous materials, few studies have been done to characterize the mechanical behavior of PGM with indentation testing. These studies can be divided into two groups. The first one consists of performing many tests in the sectioned part of the sample [17-20]. The second one consists of making only one indentation test at the surface and then applying a mixture law [1,3,21-32]. Moussa et al. [13]showed that these methods present many drawbacks for the case of carbonitrided steels. Because of these drawbacks, Moussa et al. [13] developed a method to characterize the mechanical behaviour of carbonitrided steels using spherical indentation and the inverse analysis. This method consists, in a first step, to characterize the substrate as an homogenous material since its volume is large enough. With the assumption that the variation of the hardening law in the carbonitrided layers is linear, the corresponding hardening laws are determined in a second step.

In the present paper, a carbonitrided $\mathrm{C} 12$ steel is characterized with a method based on no assumption about the evolution of the hardening law with depth. The results obtained with the two methods are compared in order to verify the validity of the assumption of linear evolution of the hardening law with depth. Finally, a validation test is proposed in order to demonstrate the reliability of the proposed method for the mechanical characterization of the carbonitrided steels with spherical indentation.

\section{Material presentation: Hardness profile and metallographic analysis}

In the previous paper, we studied two $\mathrm{C} 18$ carbonitrided steels [13]. In this paper, we propose to study a $\mathrm{C} 12$ carbonitrided steel $(0.12 \%$ of carbon before the treatment). The carbonitriding treatment was carried out at Faurecia Automotive Seating, however, details of the treatment 
cannot be outlined due to confidentiality restrictions. The hardness profiles of this steel, obtained on three different samples, are presented in Fig. 1(a). The hardness profile of the C12 carbonitrided steel can be described as follows. The hardness is approximately constant in an outer layer of thickness $\mathrm{e}_{1}$, then, the hardness decreases steadily in an intermediate zone of thickness $\mathrm{e}_{2}$. Finally, for a depth greater than $\mathrm{e}_{1}+\mathrm{e}_{2}$, the hardness is constant in a third zone which corresponds to the substrate. Fig. 1 shows that the hardness can be approximated by a linear function in the intermediate layers (Fig. 1(a)). In the proposed procedure, the values of $\mathrm{e}_{1}$ and $\mathrm{e}_{2}$ were obtained from the minimization of least squares deviation between the experimental hardness profile and the one approximated with three segments (see Fig. 1(a)). For the studied material, the thickness is $e_{1}=0.06 \mathrm{~mm}$ for the outer layer and is $e_{2}=0.29 \mathrm{~mm}$ for the intermediate layers.

\section{Fig. 1: (a) Hardness profile of the carbonitrided C12 steel obtained from three samples (b) Simplified hardening profile with the depths of the samples used the characterization}

In order to analyse the variation of the microstructure in the intermediate layers, the outer parts of the $\mathrm{C} 12$ carbonitrided samples were removed by rectification and polishing. After the polishing process using fine emery papers (up to 1200 grit) and an electrolytic polishing machine, nital etchant was used to reveal the microstructure. The microstructures of the carbonitrided $\mathrm{C} 12$ steel for different depths are presented in Fig. 2 and their positions on the hardness profile are shown in Fig. 1(a). Fig. 2 (a) shows the microstructure of the surface of the carbonitrided $\mathrm{C} 12$ steel in which very fine needles of martensite can be observed. In Fig. 2 (b), the microstructure consists of a martensite or bainite matrix containing troostite particles in the former Austenite grain boundaries. In this figure, the presence of small grains of ferrite can also be observed. The microstructure of the substrate, which contains acicular ferrite grains and pearlite, is given in Fig. 2 (c). The evolution in the depth of the microstructure demonstrates, as a consequence, changes in the plastic properties of the material that can be observed in the hardness profile given in Fig. 1.

(a) Surface $z=0 \mathrm{~mm}$

(b) Intermediate layer $z=0.18 \mathrm{~mm}$

(c) Substrate $z=0.5 \mathrm{~mm}$

Fig. 2: Microstructures of carbonitrided $\mathrm{C} 12$ steel at different depths from the surface

\section{Experimental conditions, finite element model and inverse analysis}

The experimental indentation tests were conducted using an in-house instrumented indentation bench. A spherical tungsten carbide indenter of $1 \mathrm{~mm}$ diameter was used. The Young's modulus and the Poisson's ratio of the indenter are $E=600 \mathrm{GPa}$ and $v=0.23$ respectively. The indentation load was led up to $900 \mathrm{~N}$ with a constant loading rate of $2 \mu \mathrm{m} / \mathrm{s}$. The indentation load was measured with a load sensor with a resolution of $0.02 \mathrm{~N}$. The penetration depth was measured with capacitive displacement sensors with a resolution of $0.02 \mu \mathrm{m}$. The experimental bench and its load frame compliance were presented in Ref. [16]. The ABAQUS/Standard finite element code was used for the simulation of the spherical instrumented indentation test. All mesh elements are axisymmetric four-node fully integrated elements (CAX4). Details of the mesh were given in Ref.[13]. The elastic behavior of the carbonitrited steel was assumed to be isotropic linear with $E=210 \mathrm{GPa}$ and $v=0.3$. The plastic behavior was assumed isotropic and the von Mises yield criterion was used. The behavior of the indenter was considered elastic and the properties given above were used in the FE model. The model was established with a penalty contact algorithm which uses the Coulomb's friction law, with a friction coefficient $\mu=0.1$. 
In order to identify the hardening law with spherical indentation, inverse analysis was performed. The used software SiDoLo [33] is based on a hybrid algorithm that combines three classical techniques of minimization: The gradient method, the Newton-Raphson method and the Levenberg-Marquardt method. The minimization between experimental and FE simulation curves were done with the cost functional given in this equation:

$$
L(A)=\frac{1}{h_{\max }} \int_{0}^{h_{\max }}\left(F_{\exp }-F_{\text {num }}(A)\right)^{2} d h
$$

Where $F_{\text {exp }}$ is the load obtained from experimental measurement, $F_{n u m}$ is the load obtained from simulation for a specific set of parameters and $h$ is the penetration depth.

\section{Characterization of carbonitrided C12 steel}

The hardness profile of carbonitrided steels can be described as follow: In the first zone, called "surface" of thickness $e_{1}$, the hardness remains constant while it decreases in the intermediate layers of thickness $e_{2}$. Then, when the depth is more than $e_{1}+e_{2}$, the hardness is constant and equal to the "substrate" hardness. The hardness profile can be simplified as presented in Fig. 1 (b). Considering the same variation for the hardening law of the sample we obtain the following equation:

$$
\left\{\begin{array}{l}
\sigma=\sigma_{\text {surface }} ; z<e_{1} \\
\sigma=\sigma_{\text {substrate }}+\frac{\sigma_{\text {surface }}-\sigma_{\text {substrate }}}{e_{2}}\left(e_{1}+e_{2}-z\right) ; e_{1} \leq z \leq e_{2}+e_{1} \\
\sigma=\sigma_{\text {substrate }} z>e_{2}+e_{1}
\end{array}\right.
$$

where, for each plastic strain, $\sigma_{\text {subsrate }}$ is the stress of the hardening law of the substrate and $\sigma_{\text {sufface }}$ is the stress of the hardening law of the surface.

Fig. 3 presents details of the method proposed in a previous study [13] to characterize the carbonitrided steels. The proposed method consists in making two indentation tests, the first one on the surface and the second one on the substrate (after cutting the sample). Inverse analysis, considering a homogenous sample for the substrate, leads to the determination of $\sigma_{y \text { Substrate }}$ and $n_{\text {Substrate }}$. Then, using the thickness $e_{1}$ and $e_{2}$ determined from the hardness profile and the variation of the hardening law in the intermediate layers given by equation (3), the plastic properties of the substrate and the simulation of a seven layer sample enable the determination of the mechanical properties of the surface $\sigma_{y \text { Surface }}$ and $n_{\text {Surface }}$.

From the proposed procedure, the identified parameters are $\sigma_{y}=1962 \mathrm{MPa}$ and $n=0.102$ for the surface layer and $\sigma_{y}=315 \mathrm{MPa}$ and $n=0.166$ for the substrate layer.

As was mentioned previously, this method is based on the assumption of the linear variation of the hardening law in depth. In the following part, the optimal number of intermediate layers that should be used to describe the material behaviour is determined

\section{Fig. 3: Method for the characterization of carbonitrided steels}

\section{Choice of the number of layers in numerical simulations}

In a previous paper [13], we suggested building up the FE model of the carbonitrided steel with seven layers from the surface to the substrate. The influence of the number of layers used to simulate the indentation response of the carbonitrided steel was studied. For the studied case, the Hollomon hardening law (Eq. (1)) parameters are $\sigma_{y \text { Surface }}=1962 \mathrm{MPa}$ and $n_{\text {Surface }}=0.102$ for the surface and $\sigma_{y \text { Substrate }}=315 \mathrm{MPa}$ and $n_{\text {Substrate }}=0.166$ for the substrate. The 
thickness is $e_{1}=0.06 \mathrm{~mm}$ for the surface and $e_{2}=0.29 \mathrm{~mm}$ for the intermediate layer. These parameters correspond to the identified parameters using the procedure described in section 4 .

Four different cases of gradient of mechanical properties were studied (Fig. 4). In the first case, two layers are used to represent the surface and the substrate of the carbonitrided steel. In the other cases, the intermediate layers were modeled with one layer (total of three layers), five layers (total of seven layers) and thirty layers (total of thirty-two layers). This last case is very close to a linear variation of the hardening law in the intermediate layers.

\section{Fig. 4: The four cases studied to simulate the evolution of the hardening law with depth}

The simulated indentation tests were carried out with a $0.5 \mathrm{~mm}$ radius indenter, similar to the experimental conditions. Fig. 5 shows the equivalent plastic strain distribution underneath the indenter obtained for the maximal penetration depth, i.e. $h / R=0.17$. This figure shows that the indentation response depends on the plastic flow of the intermediate layers and the substrate. The plastic strain field tends to go into the downward layers since the material hardness decreases with depth.

\section{Fig. 5: Equivalent plastic strain underneath the indenter of the carbonitrided steel simulated with 32 layers}

\section{Fig. 6: Indentation curves of a carbonitrided steel simulated with the four different models and gap between the case of 32 layers and the other cases}

Fig. 6 shows the indentation load displacement curves obtained from FE simulations of the four cases studied (2, 3, 7 and 32 layers). This figure also shows the gap between the three first cases and the 32 layer model, which is considered as a reference. We can see that using 2 or 3 layers to simulate the indentation behaviour of the carbonitrided steel leads to an under estimation of the indentation load. The maximal error between a 32 layer model is respectively $3.5 \%$ for the two layer model and 1\% for the three layer model. Fig. 6 illustrates that it is possible to have a satisfactory accuracy using 3 layers. This is an interesting observation especially when $3 \mathrm{D}$ FE models must be used for industrial structures. Using a seven layer model leads to a very accurate prediction of the indentation curve with a maximal error which is smaller than $0.3 \%$ compared to the 32 layers. It is thus shown that using seven layers leads to a very accurate prediction of the indentation curve and that it reduces the calculation time for numerical simulations. This value seems to be an optimal number of layers to simulate the carbonitrided steel.

In conclusion, the finite element simulations study has shown that seven layers are the optimal number of layers to build up the model of the carbonitrided steel. Using a greater number of layers would not increase the accuracy but it would increase the calculation time. It is also shown that the number of layers can be decreased to three when a compromise has to be made between accuracy and calculation time as in the case of industrial engineering parts. It is important to notice that these optimal numbers of layers could be different for other plastically graded materials. However, a previous study [13] performed on carbonitrided steels with different values of $e_{1}$ and $e_{2}\left(e_{2}\right.$ up to $\left.1 \mathrm{~mm}\right)$ showed that the choice of seven layers leads to accurate results. Since the carbonitrided steel can be presented as a seven layer material, the identification of the hardening laws of the seven layers means that the variation 
of the hardening law with depth of the carbonitrided steel is determined. In the following section, the carbonitrided $\mathrm{C} 12$ steel is characterized using this observation.

\section{A different approach to characterize carbonitrided steels}

In this section, we propose to characterize the C12 steel using a different approach of the one used in section 4. The aim of this new approach is to verify the assumption of linear variation of the hardening law in the intermediate layers.

Indentation tests were carried out on the seven different layers presented in Fig. 1 (b). In order to obtain these seven samples each one was cut at a given depth. The corresponding depths are given in Fig. 1 (b). These seven samples are called "substrate", "substrate + 1", ..., "substrate +5 " and "surface" as illustrated in Fig. 8.

Indentation tests were carried out on the seven different layers presented in Fig. 1 (b). In order to perform these indentation tests, seven samples were cut at different depths. The values of these depths are given in Fig. 1 (b).The seven samples are called "substrate", "substrate + 1", ..., "substrate +5 " and "surface" as illustrated in Fig. 7.

\section{Fig. 7: Diagram of the seven tested samples}

Fig. 8 shows the experimental indentation curves obtained on these seven samples. Three indentation tests were carried out on each sample. We can see in Fig. 8 that the experimental curves are quite reproducible for each case. We can also see that the maximal indentation depth (for the same applied load) increases from the surface to the substrate which is in accordance with the variation of hardness between surface and substrate. The FE simulation curves obtained from inverse analysis are compared with the experimental curves in Fig. 8. This comparison shows that the inverse analysis method reproduces with accuracy the experimental data.

\section{Fig. 8: Comparison between experimental indentation curves and FE simulation curves obtained for the seven studied samples.}

The characterization approach consists of doing seven successive identifications using inverse analysis and the load displacement curves presented in Fig. 8. For the seven cases the average curve is used for the identification. The first identification is done with the curve "substrate" obtained from the indentation of the substrate, which is considered as a homogenous material. The results of this first identification are the yield stress and the strain hardening exponent of the substrate. The second identification consists of building up a FE model with a two layer sample corresponding to "substrate" and "substrate +1 " in the inverse analysis procedure. In this second identification, the mechanical properties of the substrate are the ones previously determined with the first identification. The mechanical parameters to be identified in this second identification are those of the layer "substrate $+1 "$ ". The same procedure was applied for the other samples increasing the number of layers as shown in Fig. 7 in order to reach a complete seven layers model for the identification of the surface. The results of each previous identification are used in the following one to identify the mechanical properties of each layer. The identified parameters of each layer are given in table 1 .

\begin{tabular}{cccccccc} 
& Substrate & Substrate+1 & Substrate+2 & Substrate+3 & Substrate+4 & Substrate+5 & Surface \\
\hline \hline$\sigma_{\boldsymbol{y}}(\mathbf{M P a})$ & 315 & 649 & 824 & 1288 & 1438 & 1640 & 1985 \\
$\boldsymbol{n}$ & 0,166 & 0,146 & 0,119 & 0,082 & 0,116 & 0,097 & 0,077
\end{tabular}

Table 1: Mechanical parameters identified for each layer 
Table 1 shows a strong variation of the yield stress $\sigma_{y}$ and the strain hardening exponent $n$ in the carbonitrided layers. The results presented in table 1 are plotted in Fig. 9. The variation of the yield stress with depth is almost linear. As for the strain hardening exponent, it increases with depth. Its variation is the opposite to the variation of the yield stress. Except for the case of $0.180 \mathrm{~mm}$ depth the variation of the strain hardening exponent with depth is almost linear. It should be noted that each layer was identified using a different sample. Differences can be observed between samples even though the samples underwent the same carbonitriding process which had already been observed in the hardness profiles (Fig. 1(a)). This difference explains why the strain hardening exponent for $0.180 \mathrm{~mm}$ depth does not follow the linear variation. This result shows that the assumption about a constant strain hardening exponent in the various hardened layers of carburised, carbonitrided or nitrided steels proposed in previous studies $[29,34]$ is to be questioned.

\section{Fig. 9: Identified Hollomon hardening law parameters for the seven layers}

In order to verify the linear evolution of the hardening law with depth, the stress-strain curves corresponding to identified parameters given in table 1 are shown in Fig. 10(a) and the variation of the stress calculated for a plastic strain $\varepsilon_{p}=0$ (corresponding to the yield stress) and $\varepsilon_{p}=0.1$ with the depth from the surface are given in Fig. 10(b).

Fig. 10: Results of the characterization of the carbonitrided C12 steel:

(a) Identified stress-strain curves for each layer

(b) Variation of stress with depth for two plastic strain values: 0 and 0.1

The identified hardening laws of the surface obtained from the two procedures are very close. Fig. 10(b) illustrates that the variation of the stress (for $\varepsilon_{p}=0$ and $\varepsilon_{p}=0.1$ ) with the depth is almost linear. This result shows that the assumption of the linear variation of the hardening law in the intermediate layers used in a previous study [13] is appropriate.

The procedure proposed in this paragraph is a method for the mechanical characterization of carbonitrided steels. The drawback is that it requires complex preparation of the samples and involves seven inverse analysis calculations to determine the mechanical properties of the surface layer. It is thus not a simple method to determine the mechanical properties of PGM. This procedure allowed us to show that the assumption of a linear variation of the hardening law in the intermediate layers is valid for carbonitrided steels.

\section{Validation test}

In order to verify that the results obtained give a good response of the C12 carbonitrided steel under different indentation load conditions, an instrumented roller indentation bench was developed see (Fig. 11). This test consists in applying a load to a roller which penetrates into the carbonitrided steel sample. During the test, the load and the penetration depth are measured continuously in order to obtain a load displacement curve. The penetration depth is obtained by measuring the distance between the center of the roller and the initial surface of the sample. The roller diameter is $4 \mathrm{~mm}$ and the sample width is $4.6 \mathrm{~mm}$, corresponding to the contact length. The corresponding FE simulation model, presented in Fig. 12, is composed of 282000 linear hexahedral elements of type C3D8 in ABAQUS/standard FE software. Thanks to the symmetries of the test, only a quarter of the sample-roller set was modeled, boundary conditions are presented in Fig. 12. The behavior of 
the tungsten carbide roller was assumed to be isotropic linear elastic with $E=600 \mathrm{GPa}$ and $v=0.23$.

Fig. 11: Diagram of the instrumented roller indentation test.

Fig. 12: Finite element simulation model of the instrumented roller indentation test.

The material response to the instrumented roller indentation test is conditioned by the hardening laws of the carbonitrided layers as well as that of the substrate. The validation test is based on the comparison between the experimental load-displacement curve with that obtained from FE simulation using the hardening law evolution identified with spherical indentation. The comparison of the experimental and the FE simulation load displacement curve is presented in Fig. 13. It can be observed in this figure that the gap between experimental and FE simulation curves does not exceed 4\%, which is adequate, given the scatter of mechanical properties of carbonitrided studied samples (see section6). The results presented in Fig. 13 show that the identified hardening laws for the carbonitrided steels are valid and allow us to predict the behavior of the material. These results also demonstrate the reliability of the proposed method for the mechanical characterization of the carbonitrided steels with spherical indentation.

\section{Fig. 13: Instrumented roller indentation curves obtained from experimental testing and finite elements simulation.}

\section{Conclusion}

An experimental and numerical investigation on carbonitrided steels behaviour during an indentation test is proposed. In the first part, an experimental study of a carbonitrided steel has illustrated the variation of the mechanical properties in the intermediate layers with changes in the microstructure.

In the second part, a numerical study has shown that the optimal number of layers to model a carbonitrided steel is seven. It has also been shown that using three layers could provide a relatively good compromise between accuracy and the calculation time for complex engineering structure simulations.

A complete identification procedure on seven layers was presented and the carbonitrided steel was identified in different parts, each corresponding to a different value for the depth. The results show that the assumption of a linear variation of the hardening law in the intermediate layers is valid. Using this assumption, the identified hardening laws for the carbonitrided steels enable the material response of the $\mathrm{C} 12$ carbonitrided steel, under different indentation load conditions, to be predicted. As a consequence, it is demonstrated that the proposed procedure, which involves two indentation tests in the substrate and the surface and a hardness profile, is an efficient method for the identification of the mechanical properties of plastically graded materials.

\section{References}

[1] Y.P. Cao, J. Lu, J. Mater. Res. 19 (2004) 1703-1716.

[2] V. Garnier, G. Corneloup, Proc. Ultrason. Int. 1995. 34 (1996) 401-404.

[3] A.E. Giannakopoulos, Int. J. Solids Struct. 39 (2002) 2495-2515.

[4] J. Wan, A. Fatemi, Int. J. Fatigue. 17 (1995) 15-24. 
[5] A. Nayebi, R. El Abdi, O. Bartier, G. Mauvoisin, Mech. Mater. 34 (2002) 243-254.

[6] J.-M. Collin, G. Mauvoisin, O. Bartier, R. El Abdi, P. Pilvin, Mater. Sci. Eng. A. 501 (2009) 140-145.

[7] H. Lee, J.H. Lee, G.M. Pharr, J. Mech. Phys. Solids. 53 (2005) 2037-2069.

[8] N. Ogasawara, N. Chiba, X. Chen, Mech. Mater. 41 (2009) 1025-1033.

[9] M. Zhao, N. Ogasawara, N. Chiba, X. Chen, Acta Mater. 54 (2006) 23-32.

[10] J.-M. Collin, G. Mauvoisin, P. Pilvin, Mater. Des. 31 (2010) 636-640.

[11] J.-M. Collin, T. Parenteau, G. Mauvoisin, P. Pilvin, Comput. Mater. Sci. 46 (2009) 333338.

[12] N. Huber, C. Tsakmakis, J. Mech. Phys. Solids. 47 (1999) 1569-1588.

[13] C. Moussa, O. Bartier, G. Mauvoisin, P. Pilvin, G. Delattre, J. Mater. Res. 27 (2012) 2027.

[14] C. Moussa, X. Hernot, O. Bartier, G. Delattre, G. Mauvoisin, J. Mater. Sci. 49 (2014) 592-603.

[15] J.H. Hollomon, Trans AIME. 162 (1945) 268.

[16] O. Bartier, X. Hernot, G. Mauvoisin, Mech. Mater. 42 (2010) 640-656.

[17] N.A. Branch, N.K. Arakere, G. Subhash, M.A. Klecka, Int. J. Plast. 27 (2011) 728-738.

[18] Y. Ma, Y. Zhang, X. Yao, X. Zhang, X. Shu, B. Tang, Surf. Coat. Technol. 226 (2013) $75-81$.

[19] G. Bolelli, B. Bonferroni, H. Koivuluoto, L. Lusvarghi, P. Vuoristo, Surf. Coat. Technol. 205 (2010) 2209-2217.

[20] I. Campos-Silva, E. Hernández-Sánchez, G. Rodríguez-Castro, H. Cimenoglu, J.L. Nava-Sánchez, A. Meneses-Amador, et al., Surf. Coat. Technol. 232 (2013) 173-181.

[21] I.S. Choi, M. Dao, S. Suresh, J. Mech. Phys. Solids. 56 (2008) 157-171.

[22] I.S. Choi, A.J. Detor, R. Schwaiger, M. Dao, C.A. Schuh, S. Suresh, J. Mech. Phys. Solids. 56 (2008) 172-183.

[23] D. Chicot, L. Gil, K. Silva, F. Roudet, E.S. Puchi-Cabrera, M.H. Staia, et al., Thin Solid Films. 518 (2010) 5565-5571.

[24] J. Lesage, D. Chicot, Surf. Eng. 15 (1999) 447-453.

[25] J. Lesage, D. Chicot, L. Nosei, J. Feugeas, Surf. Eng. 25 (2009) 93-96.

[26] F. Zhang, R. Saha, Y. Huang, W.D. Nix, K.C. Hwang, S. Qu, et al., Int. J. Plast. 23 (2007) 25-43.

[27] M. Zhao, Y. Xiang, J. Xu, N. Ogasawara, N. Chiba, X. Chen, Thin Solid Films. 516 (2008) 7571-7580.

[28] J.A. Knapp, J.F. Browning, J. Nucl. Mater. 350 (2006) 147-152.

[29] A. Nayebi, R. El Abdi, O. Bartier, G. Mauvoisin, M. Buisson, J. Mater. Process. Technol. 141 (2003) 276-283.

[30] T. Nakamura, T. Wang, S. Sampath, Acta Mater. 48 (2000) 4293-4306.

[31] Y. Gu, T. Nakamura, L. Prchlik, S. Sampath, J. Wallace, Mater. Sci. Eng. A. 345 (2003) 223-233.

[32] A. Nayebi, R. El Abdi, O. Bartier, G. Mauvoisin, Mater. Sci. Eng. A. 333 (2002) 160169.

[33] P. Pilvin, Phd thesis, Université Pierre et Marie Curie, 1990.

[34] H. Elghazal, G. Lormand, A. Hamel, D. Girodin, A. Vincent, Mater. Sci. Eng. A. 303 (2001) 110-119. 


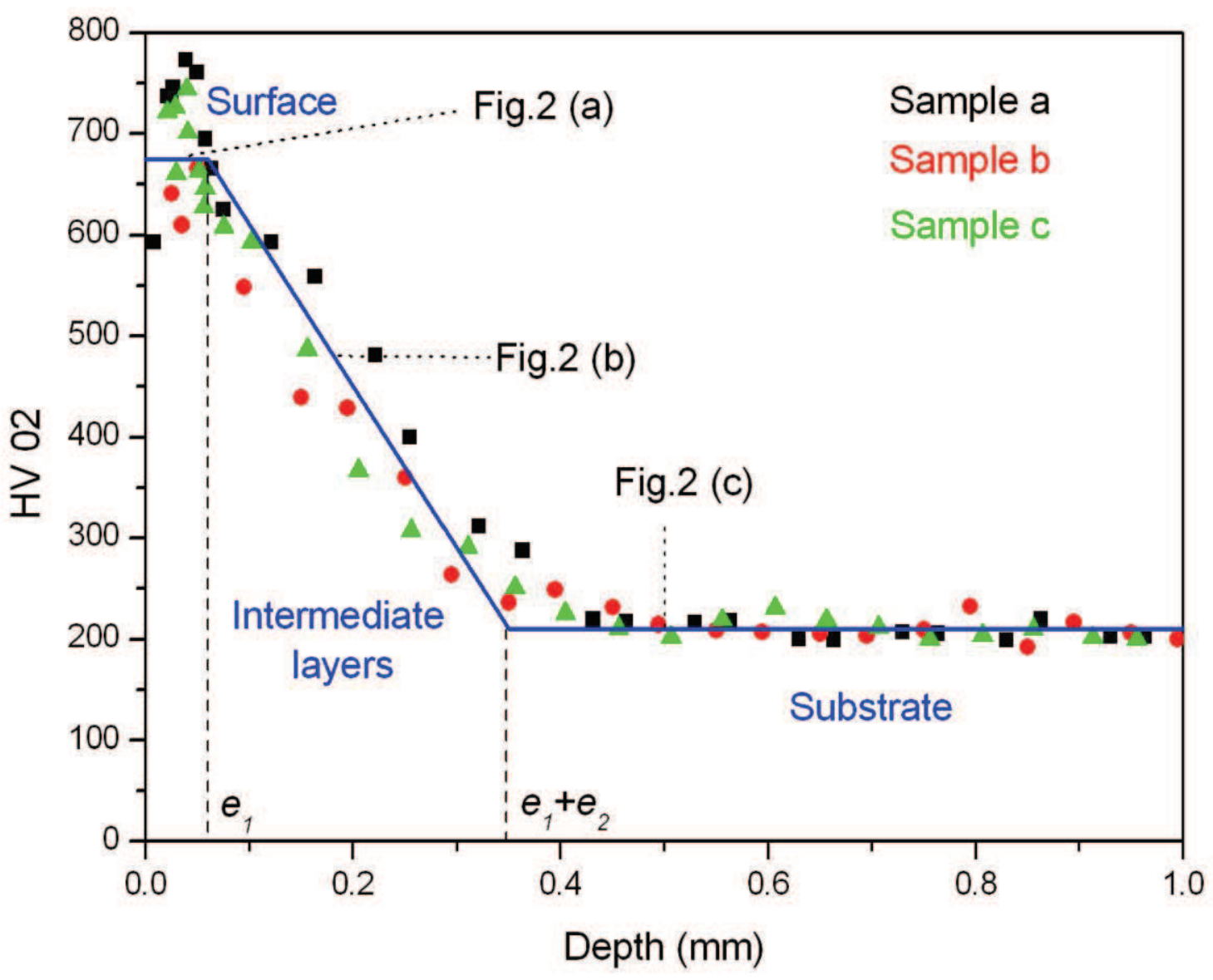

Figure 1a 


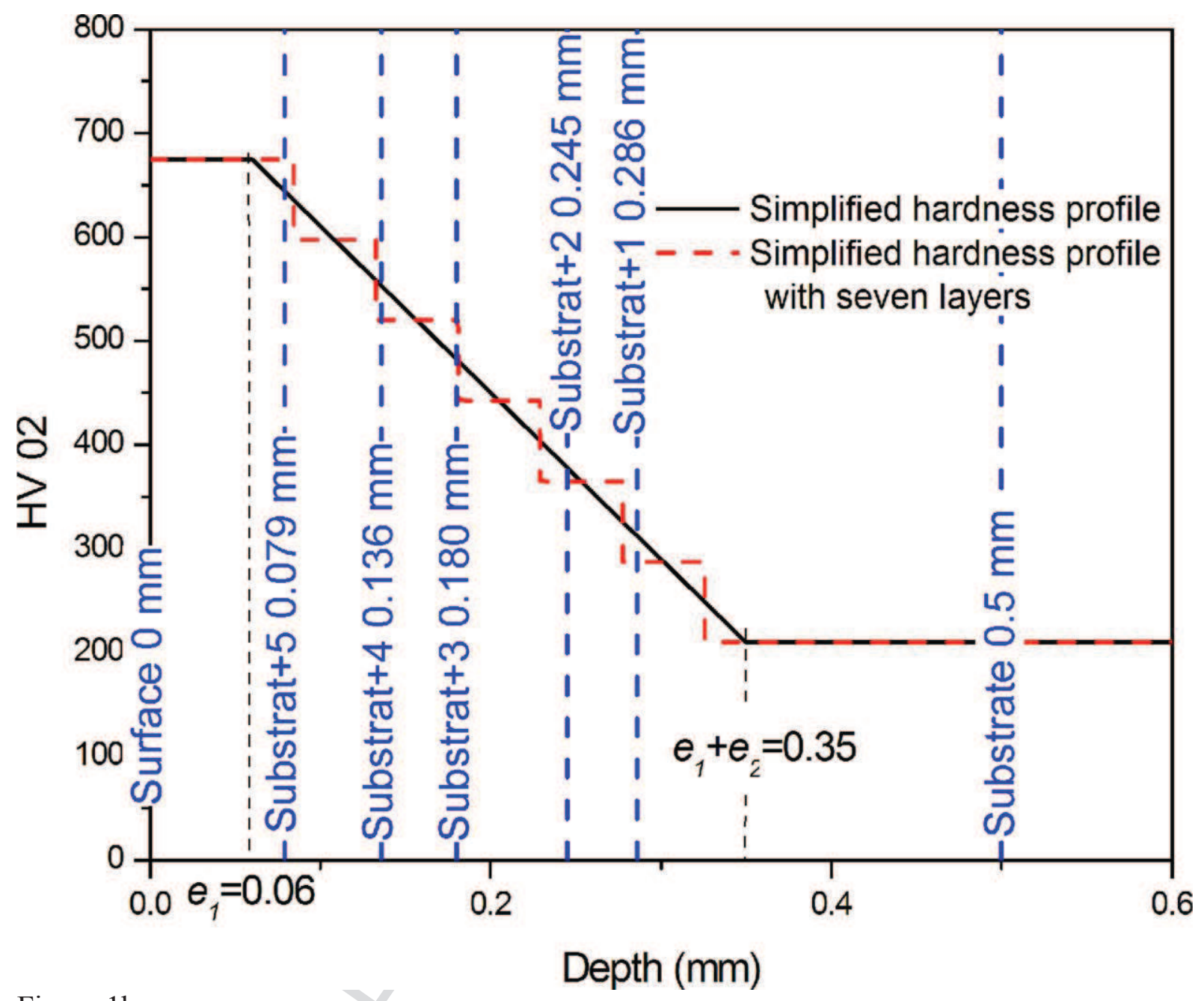

Figure $1 b$ 


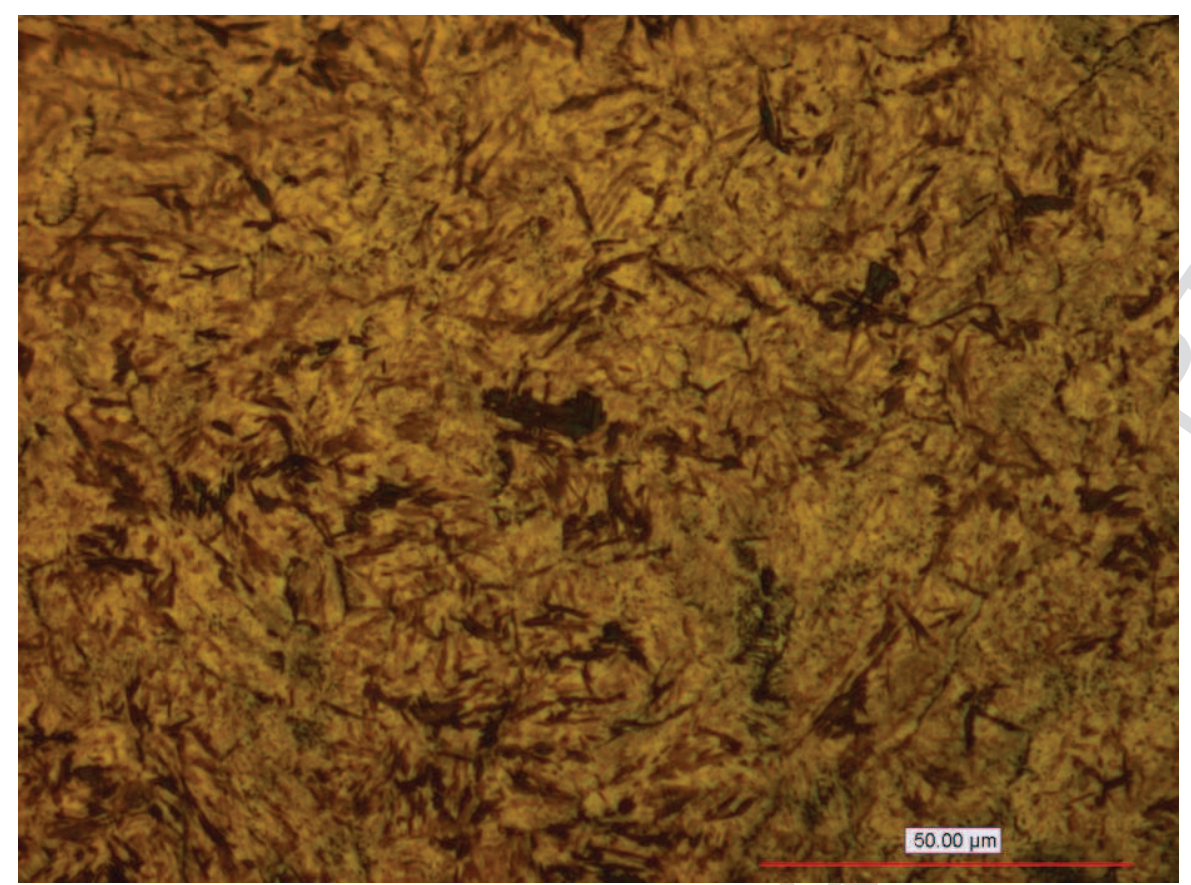

Figure 2a

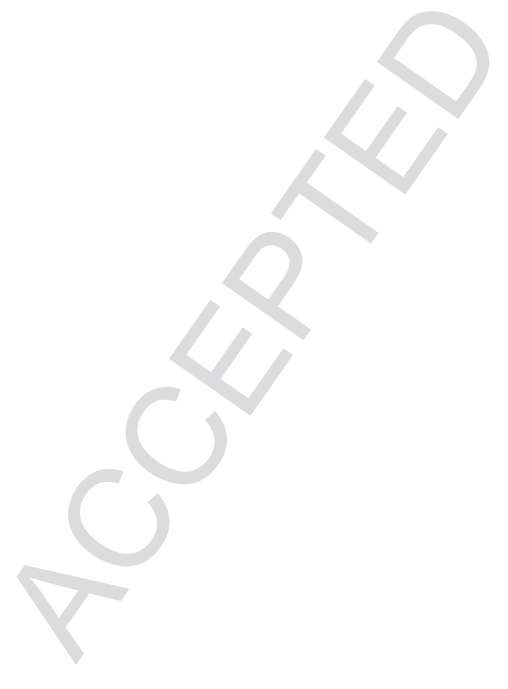




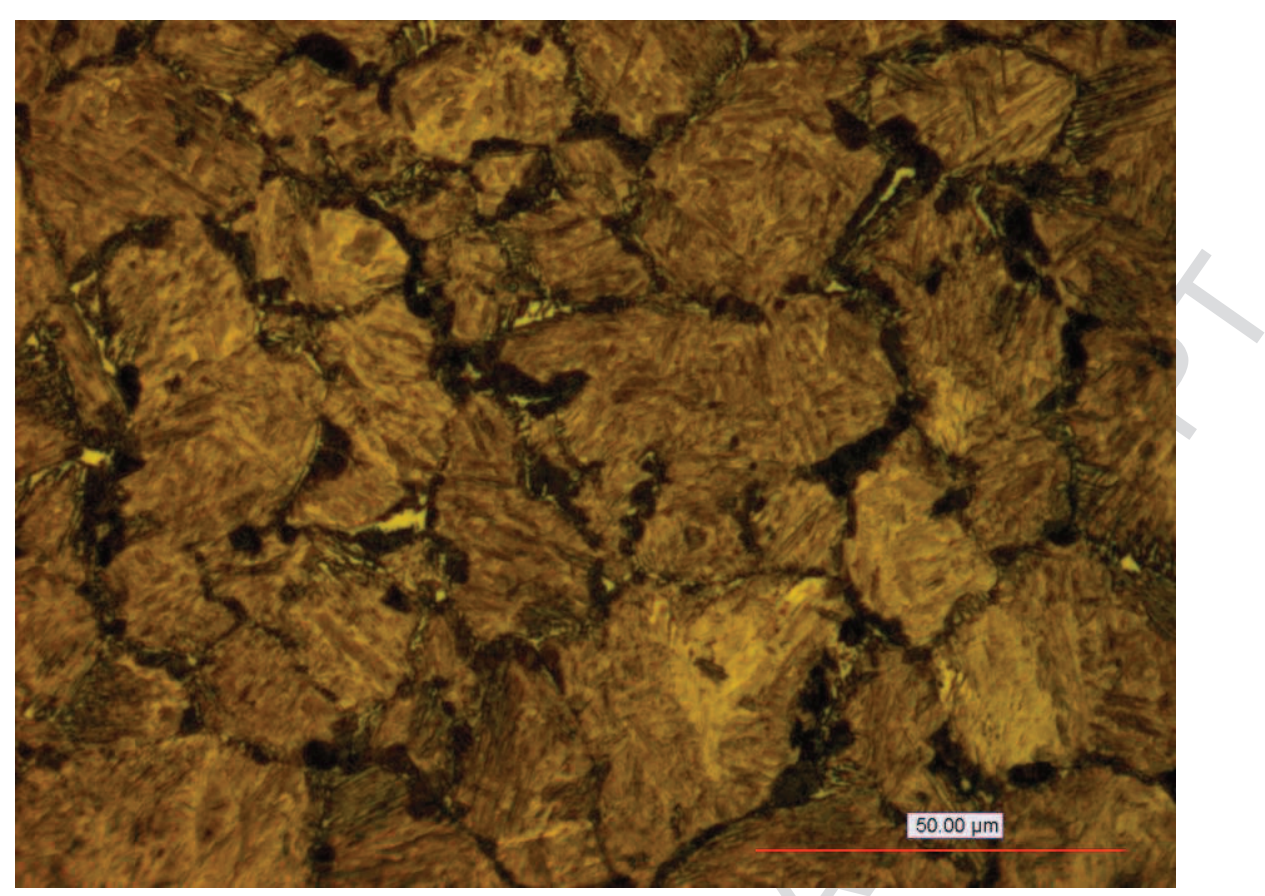

Figure $2 b$

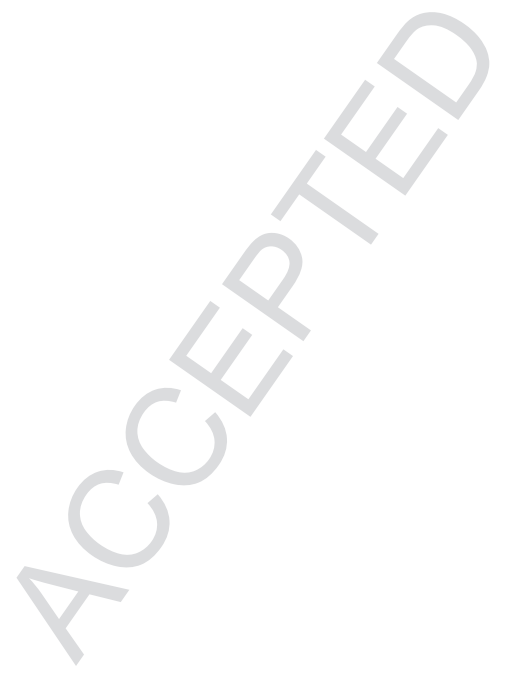




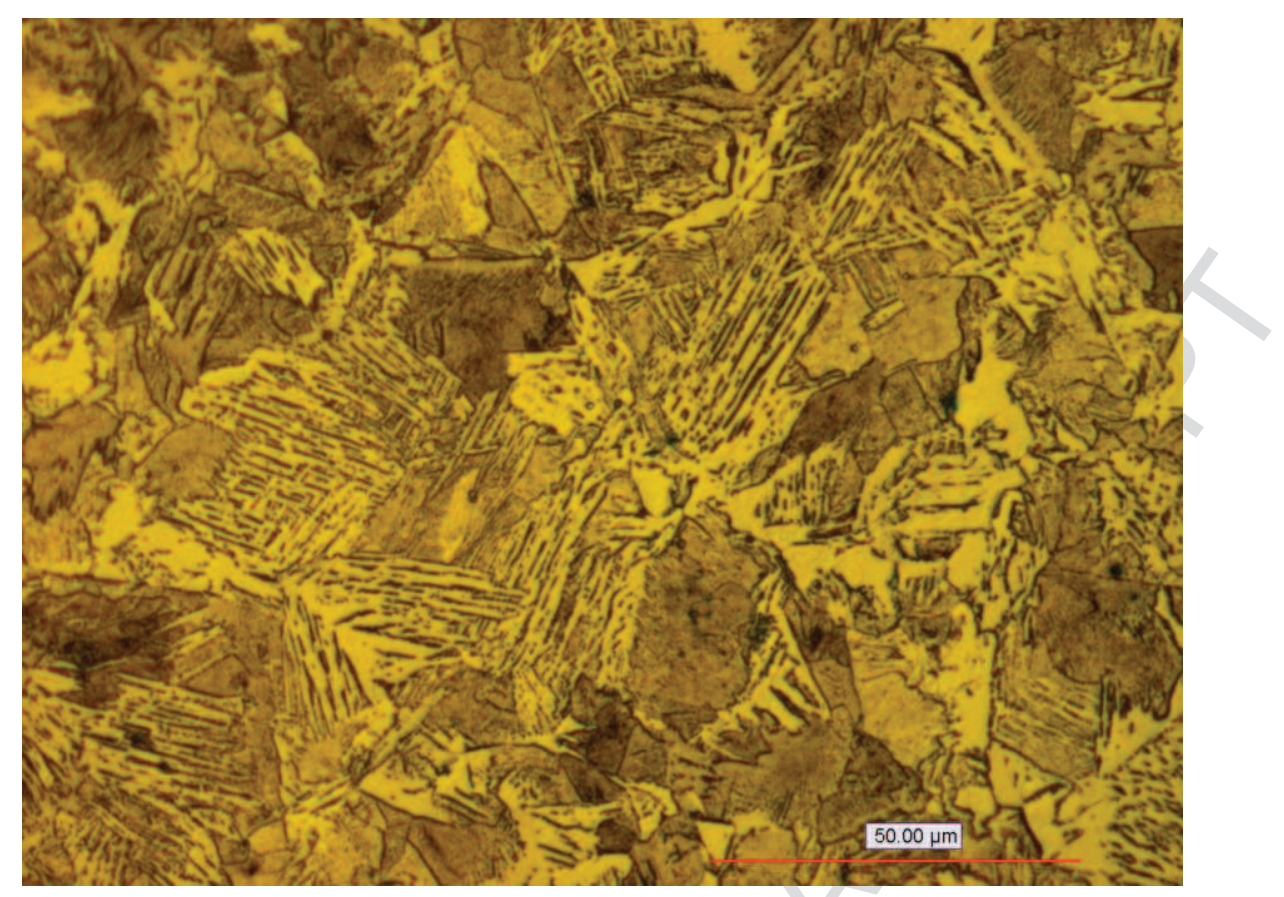

Figure 2c

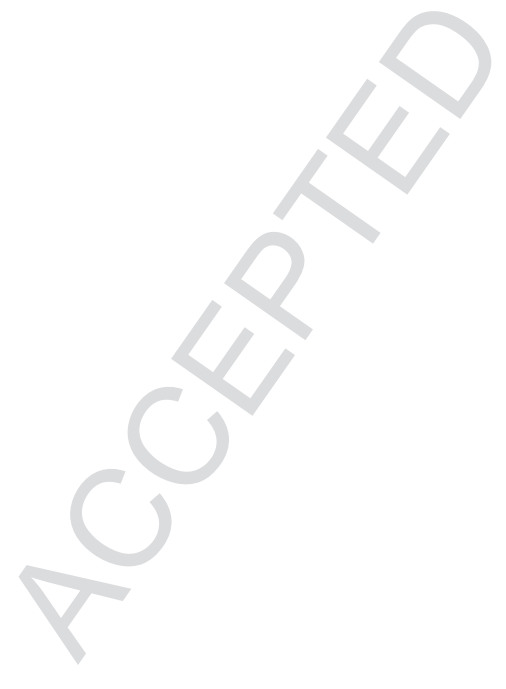




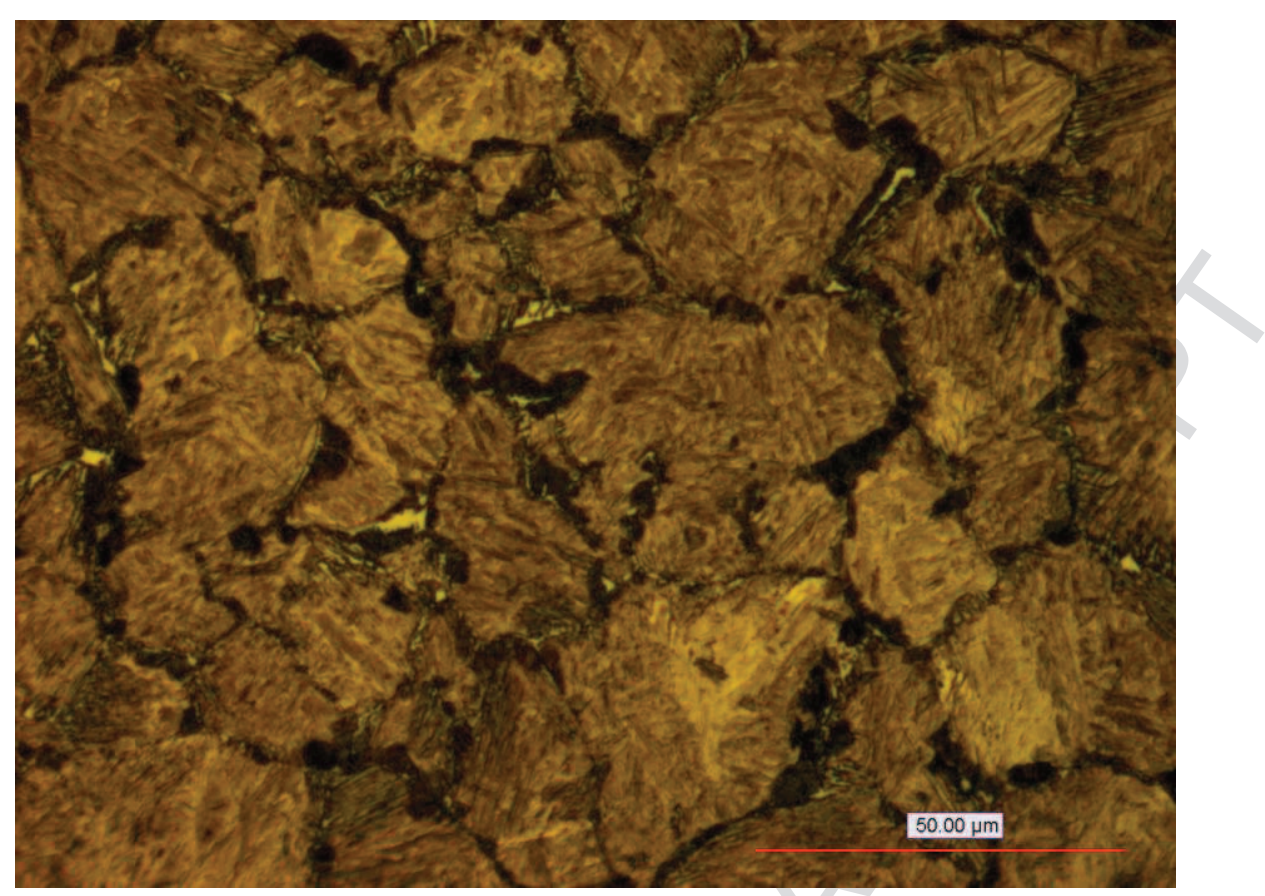

Figure 2d

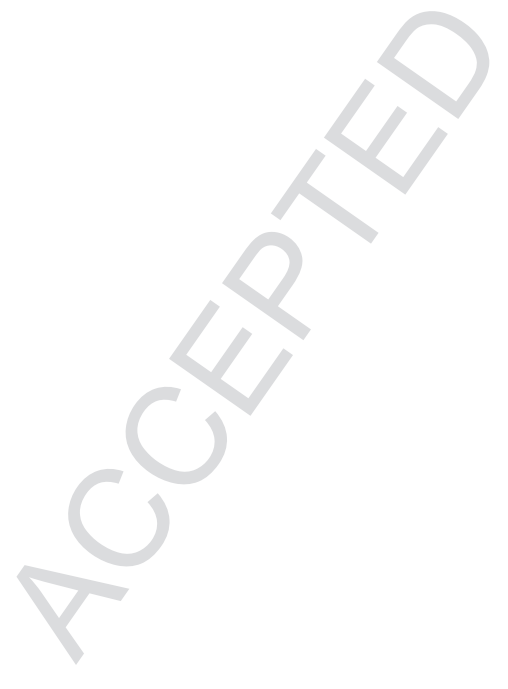




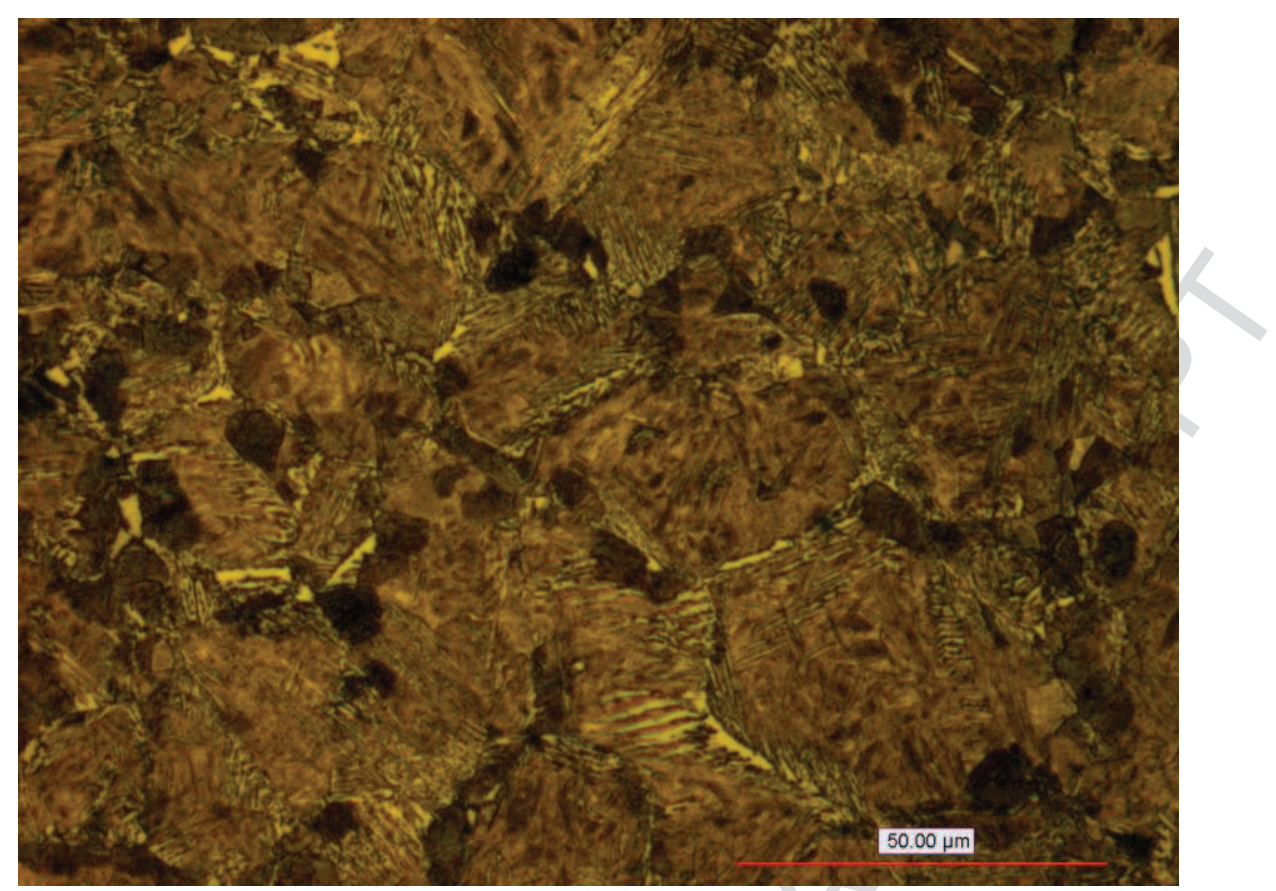

Figure 2e

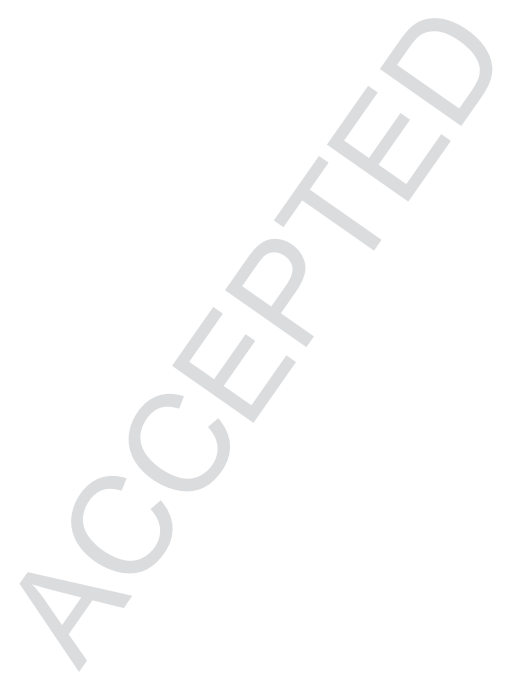




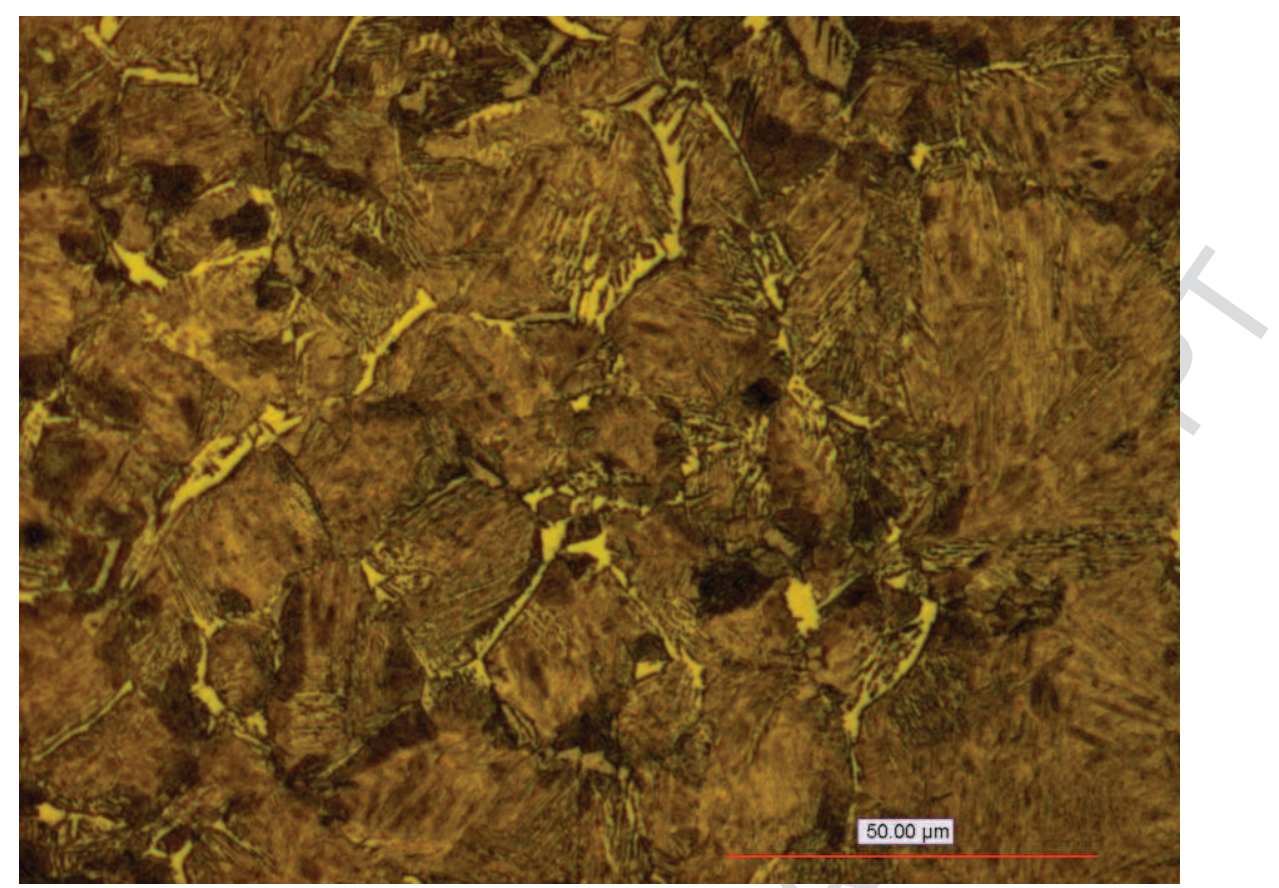

Figure $2 \mathrm{f}$

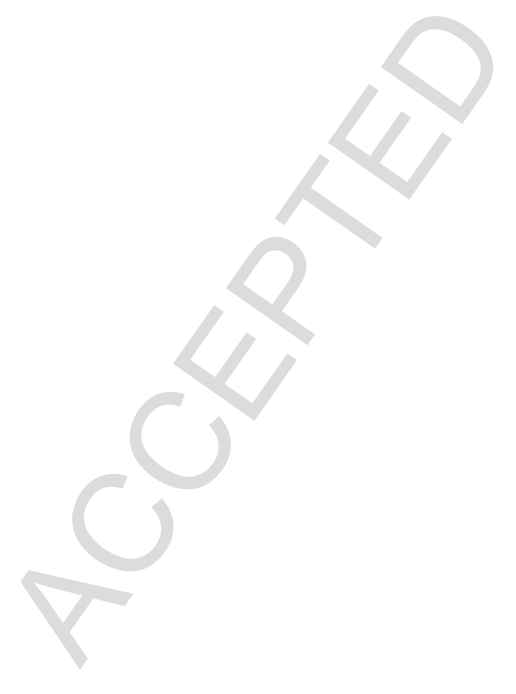




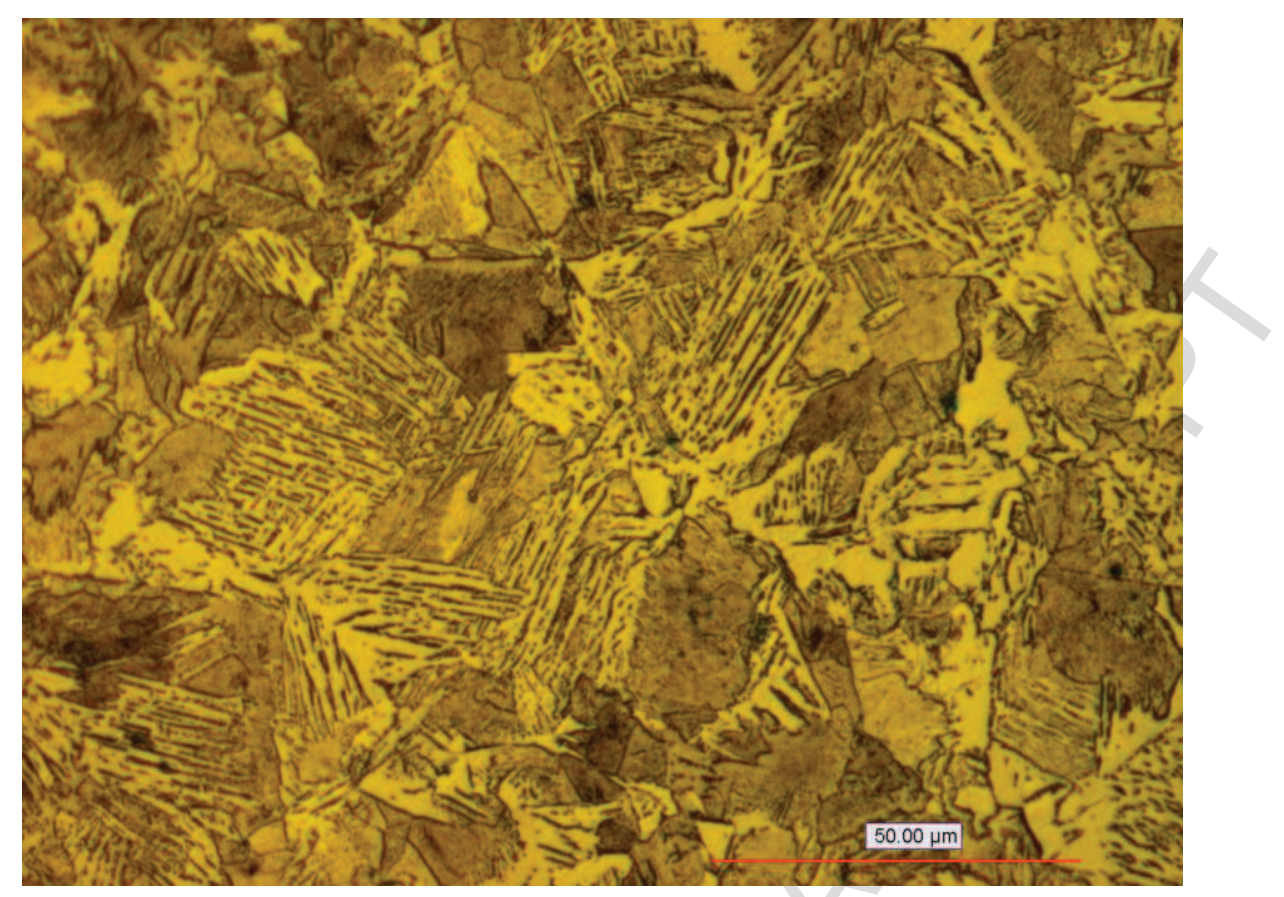

Figure $2 \mathrm{~g}$

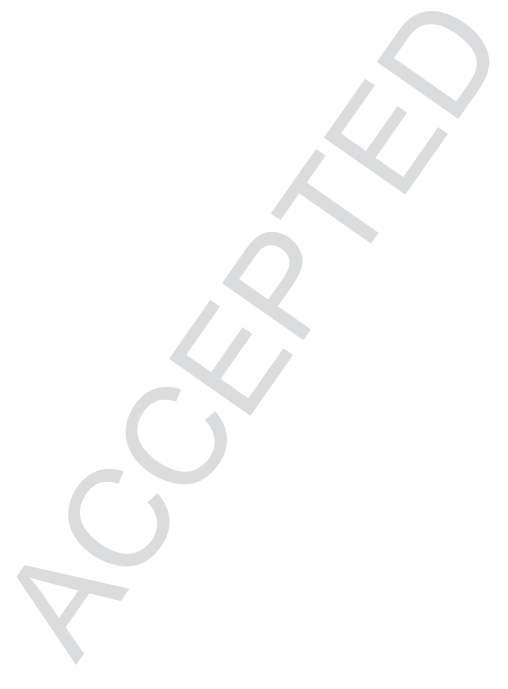




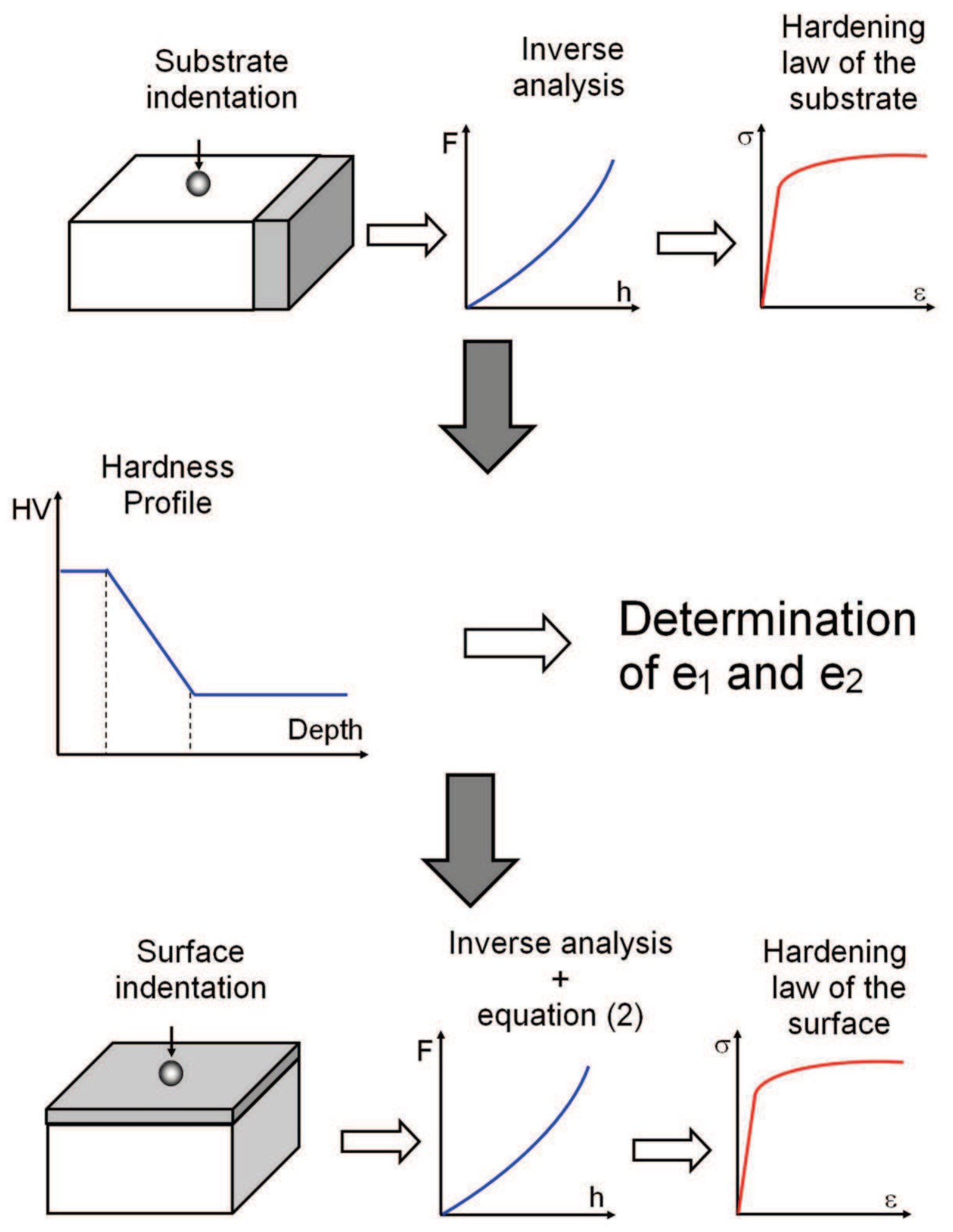

Figure 3 


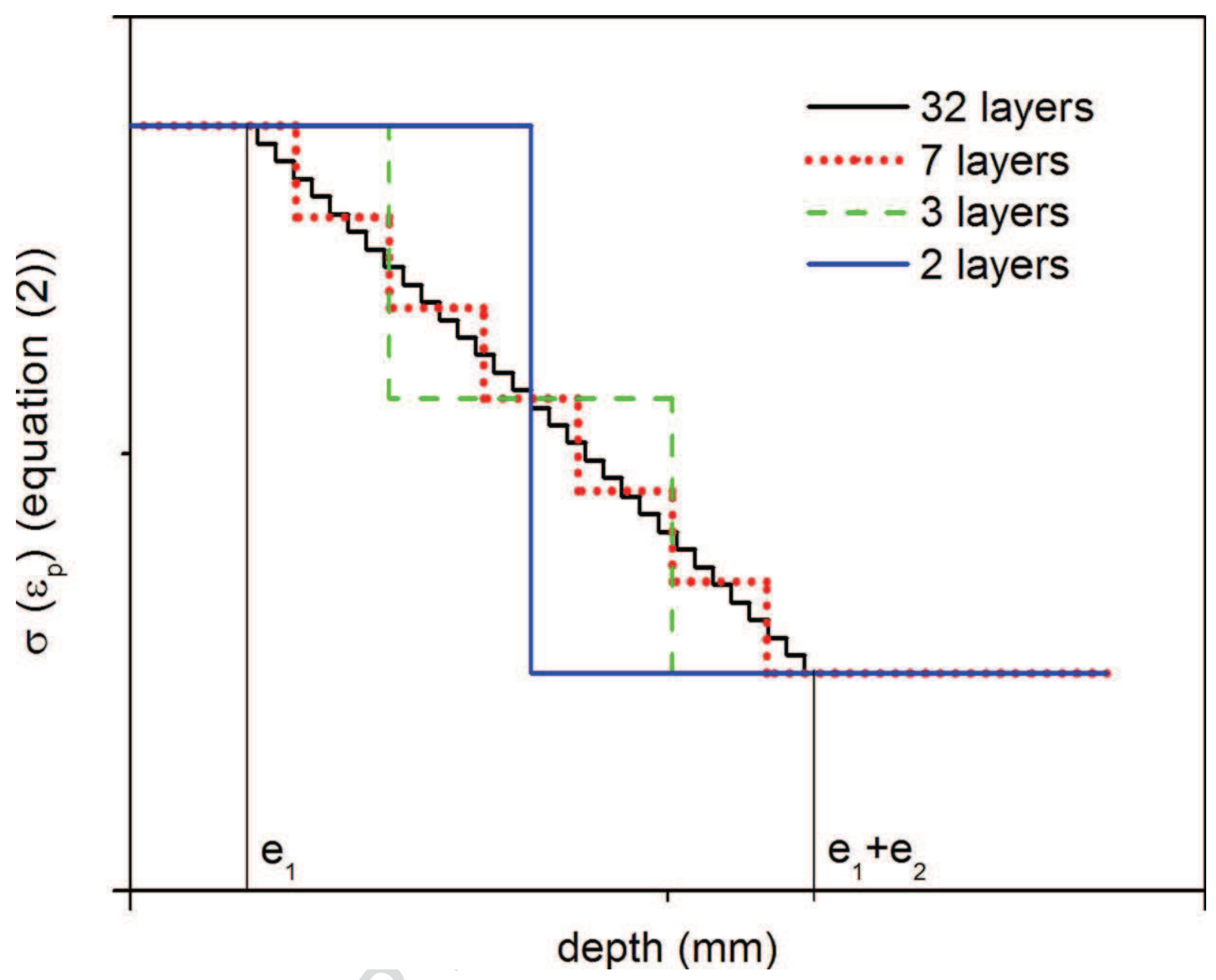

Figure 4 


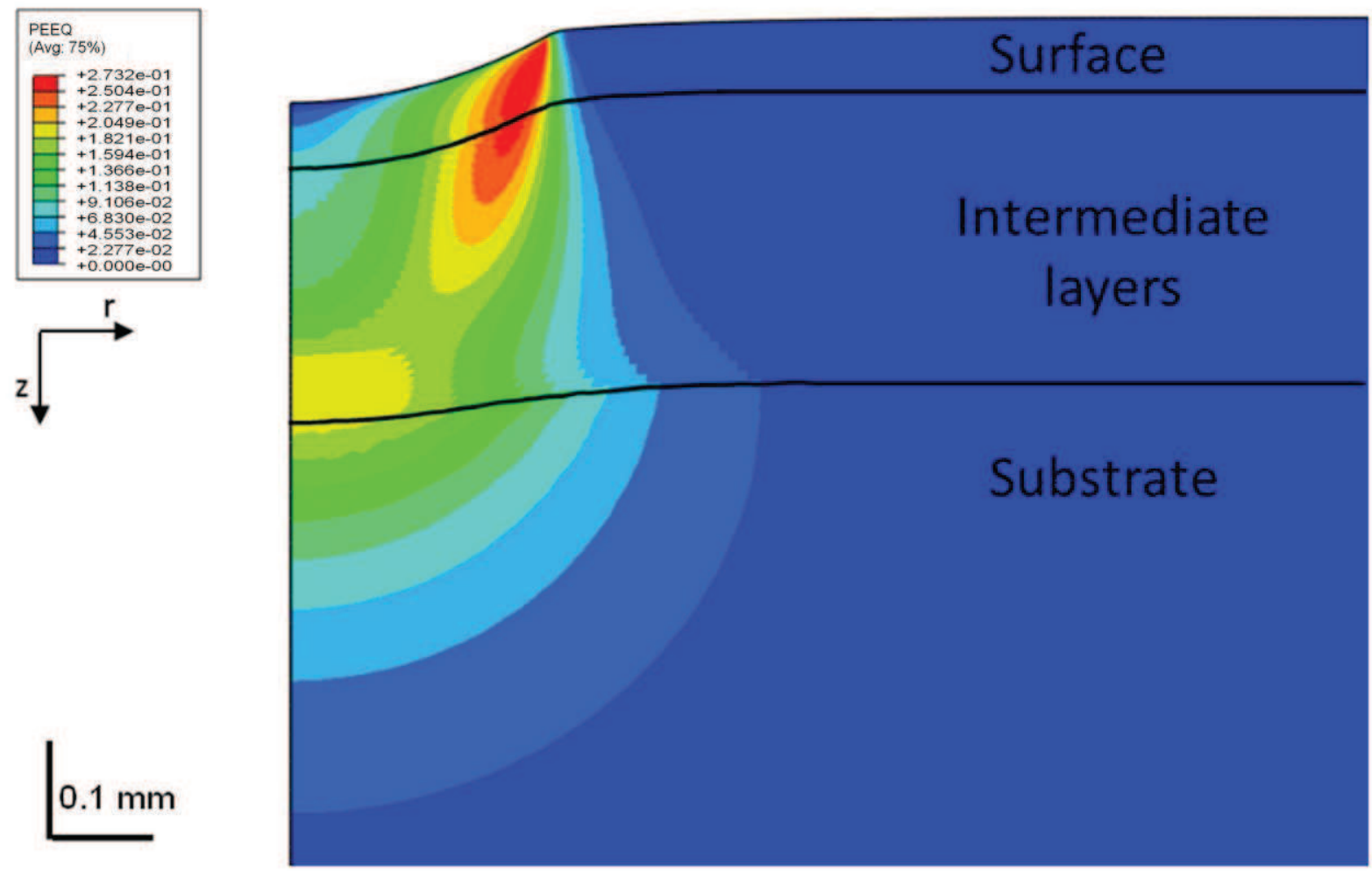

Figure 5 


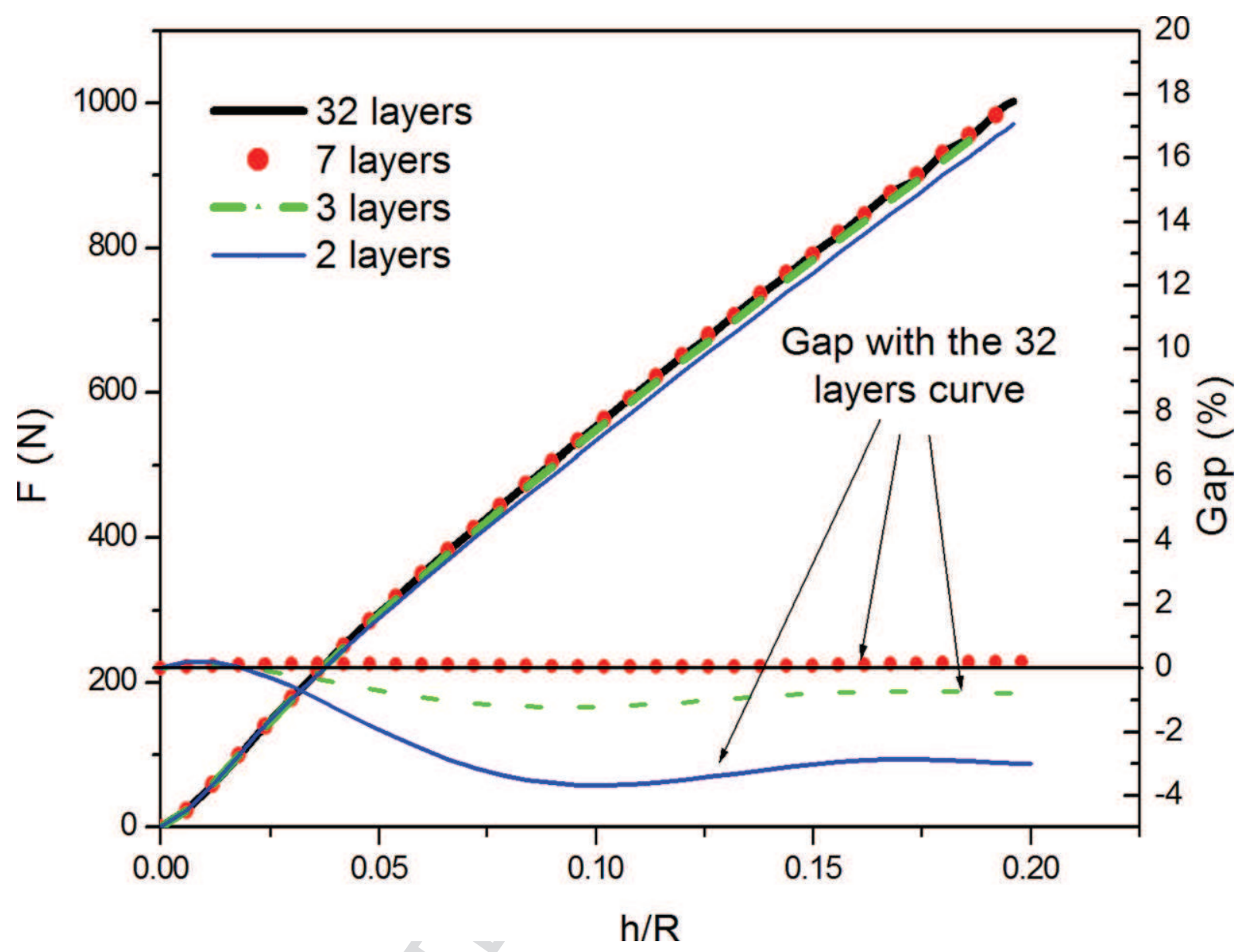

Figure 6 
Surface

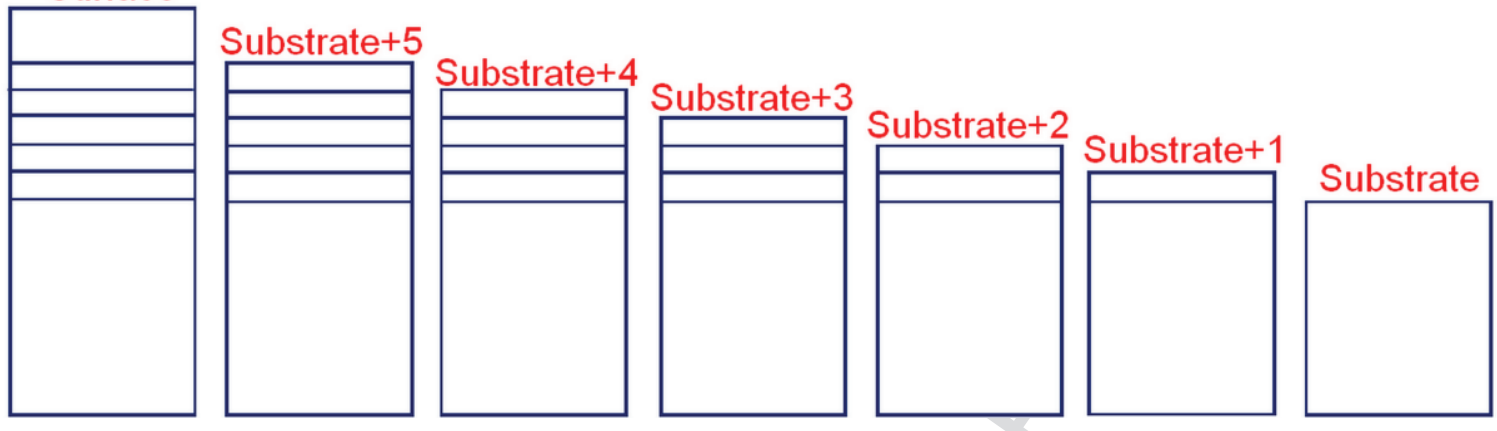

Figure 7 


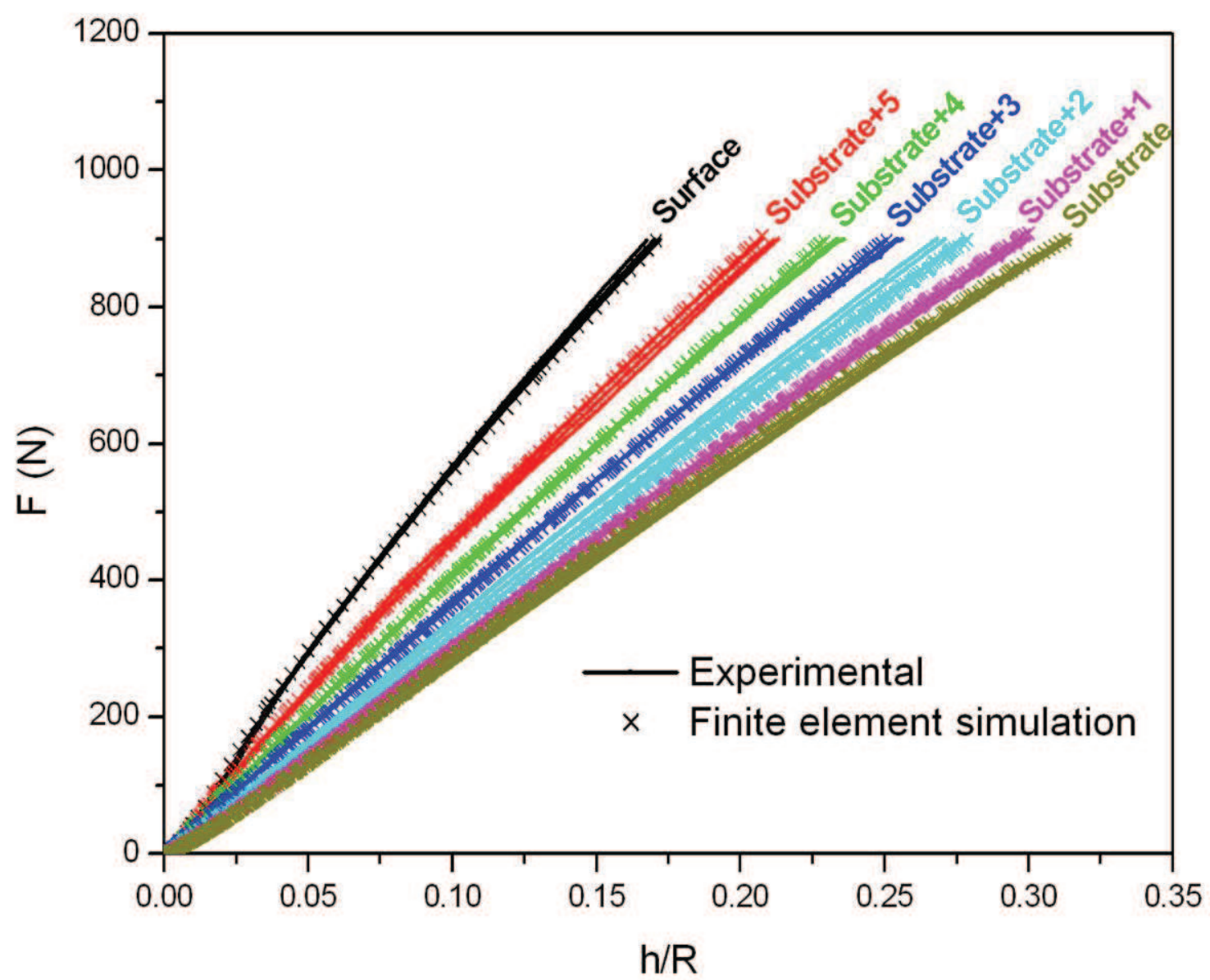

Figure 8 


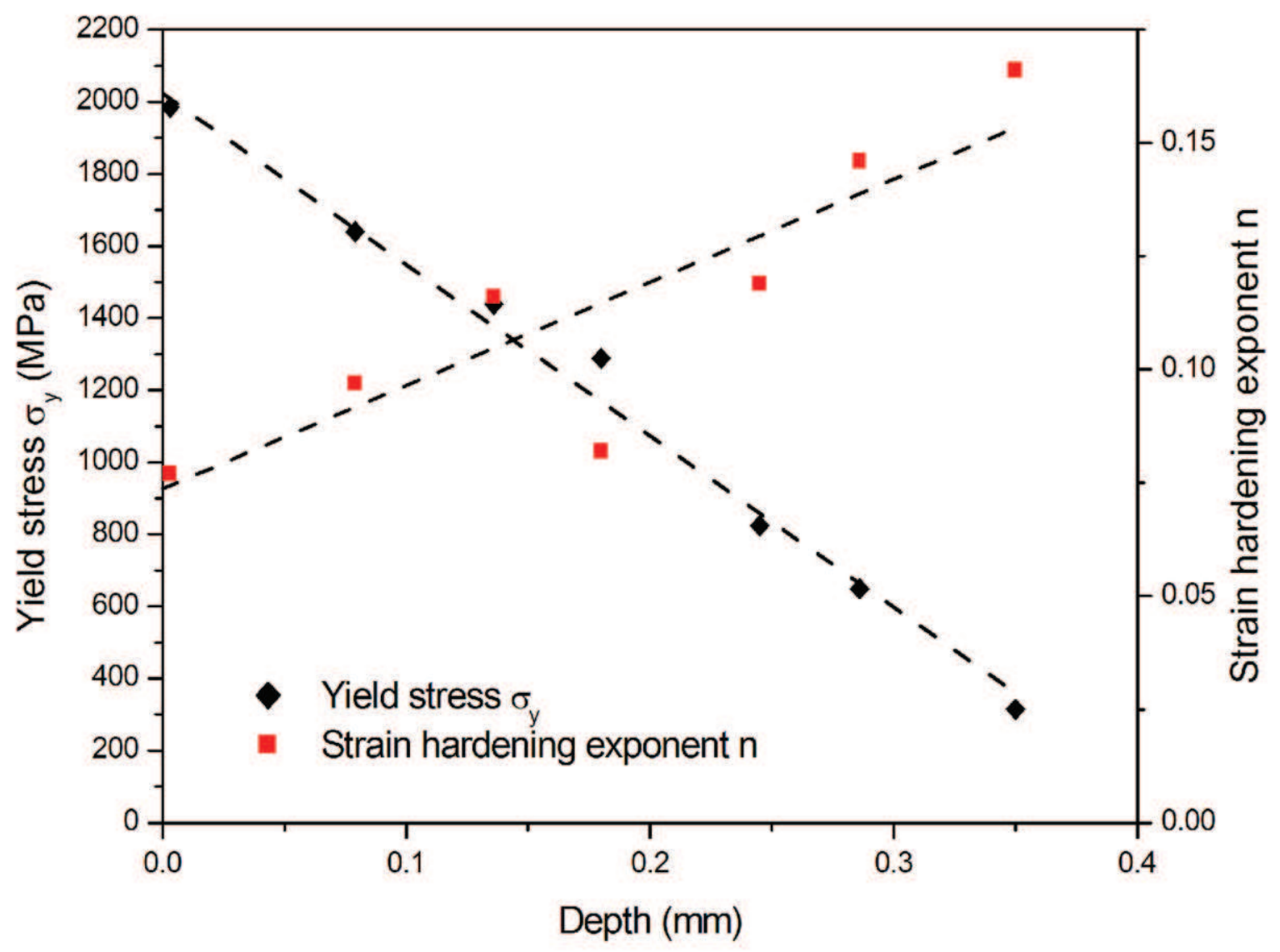

Figure 9 


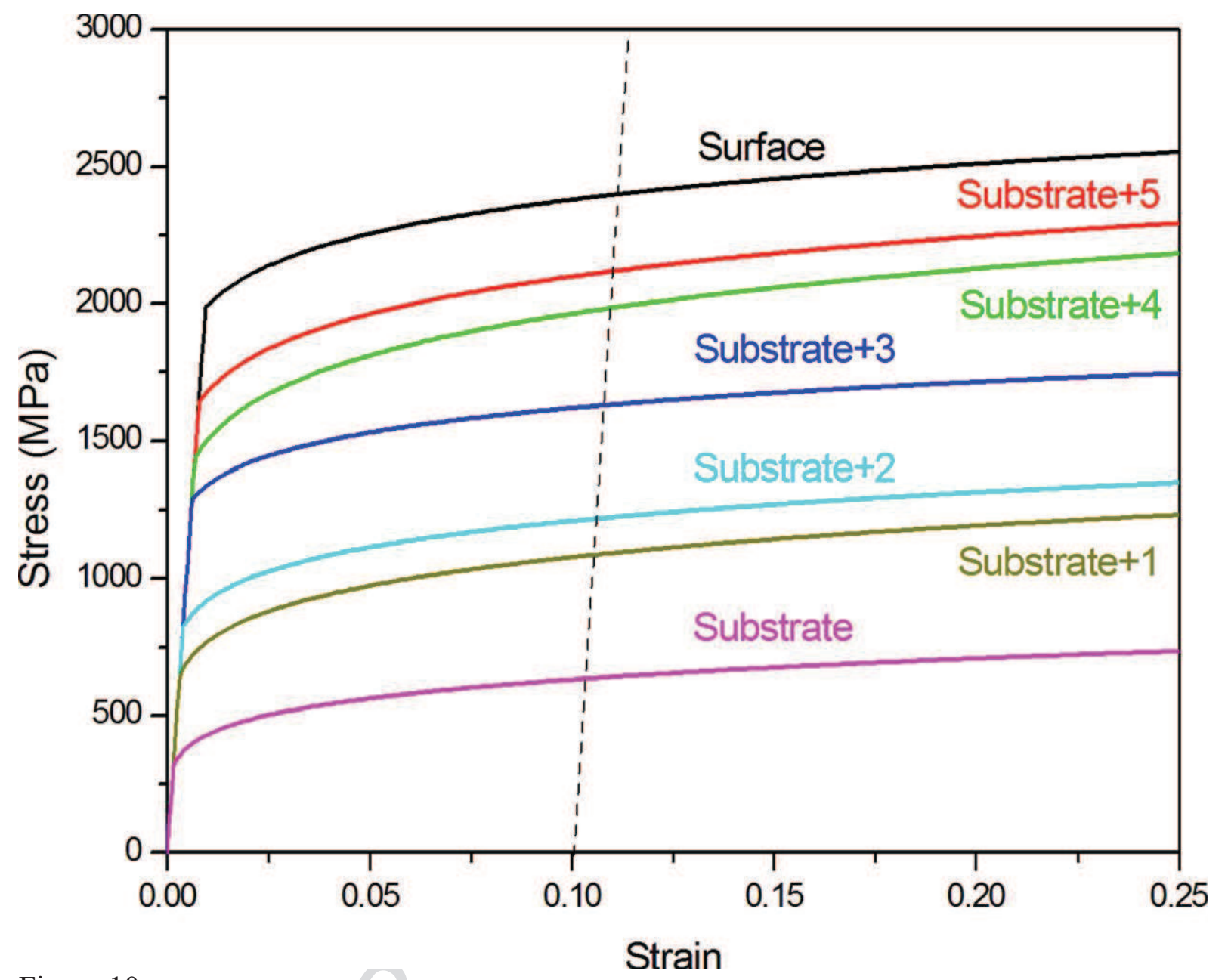

Figure 10a 


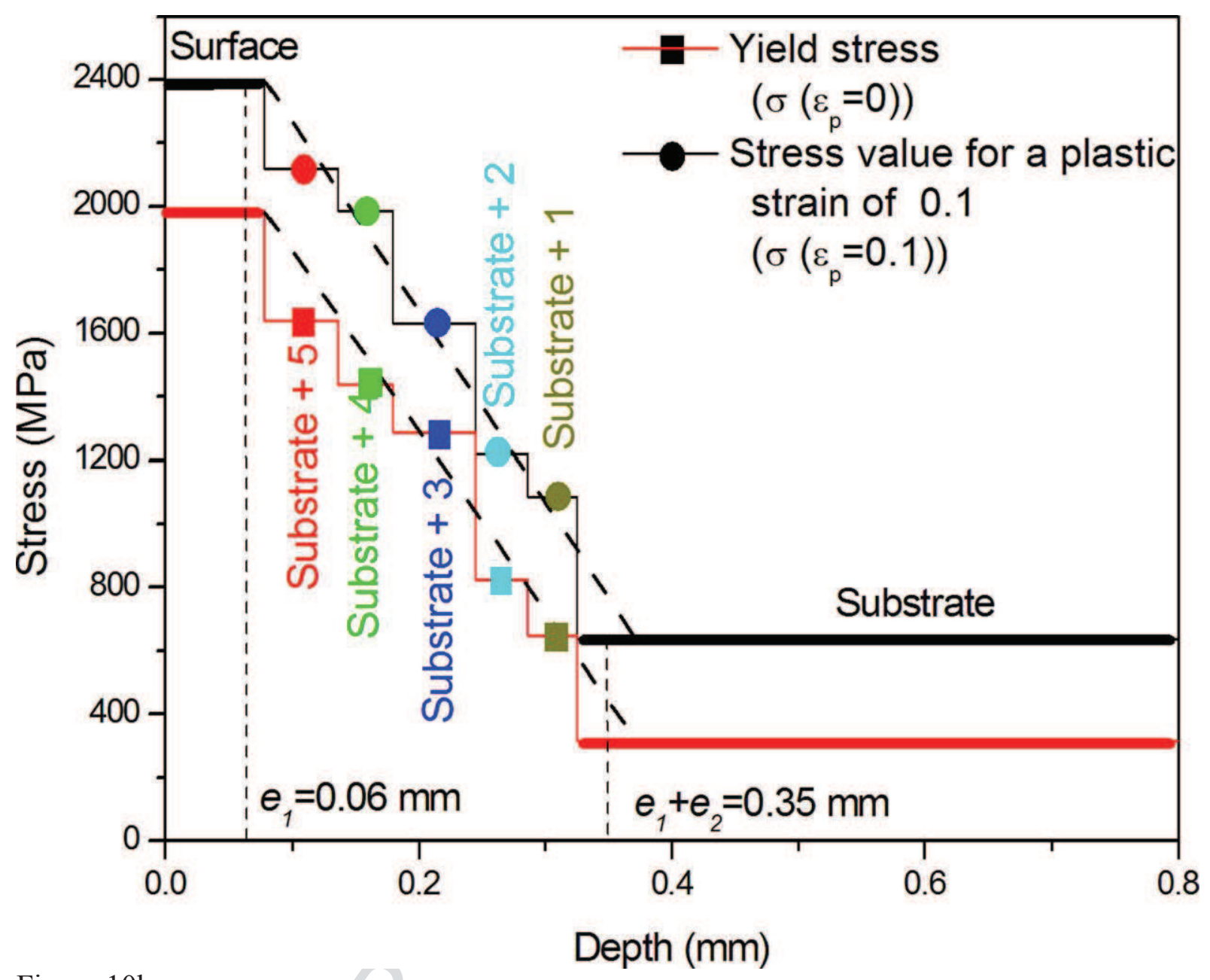

Figure 10b 


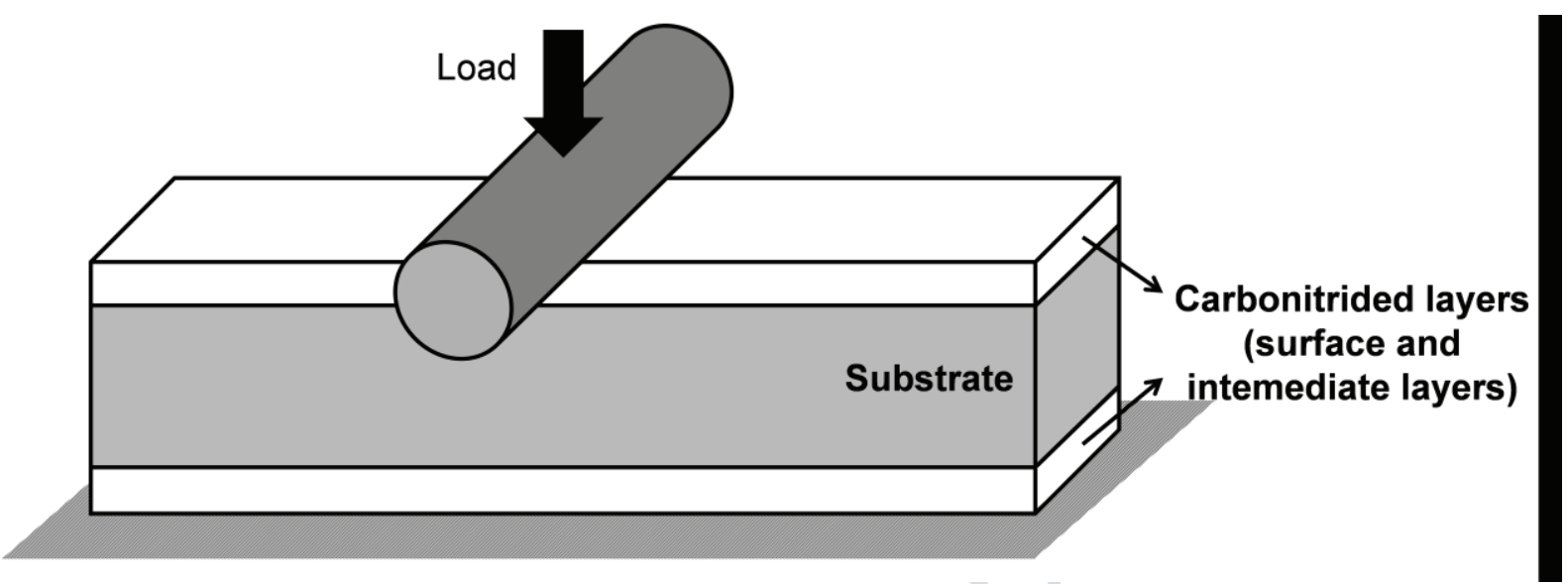

Figure 11 


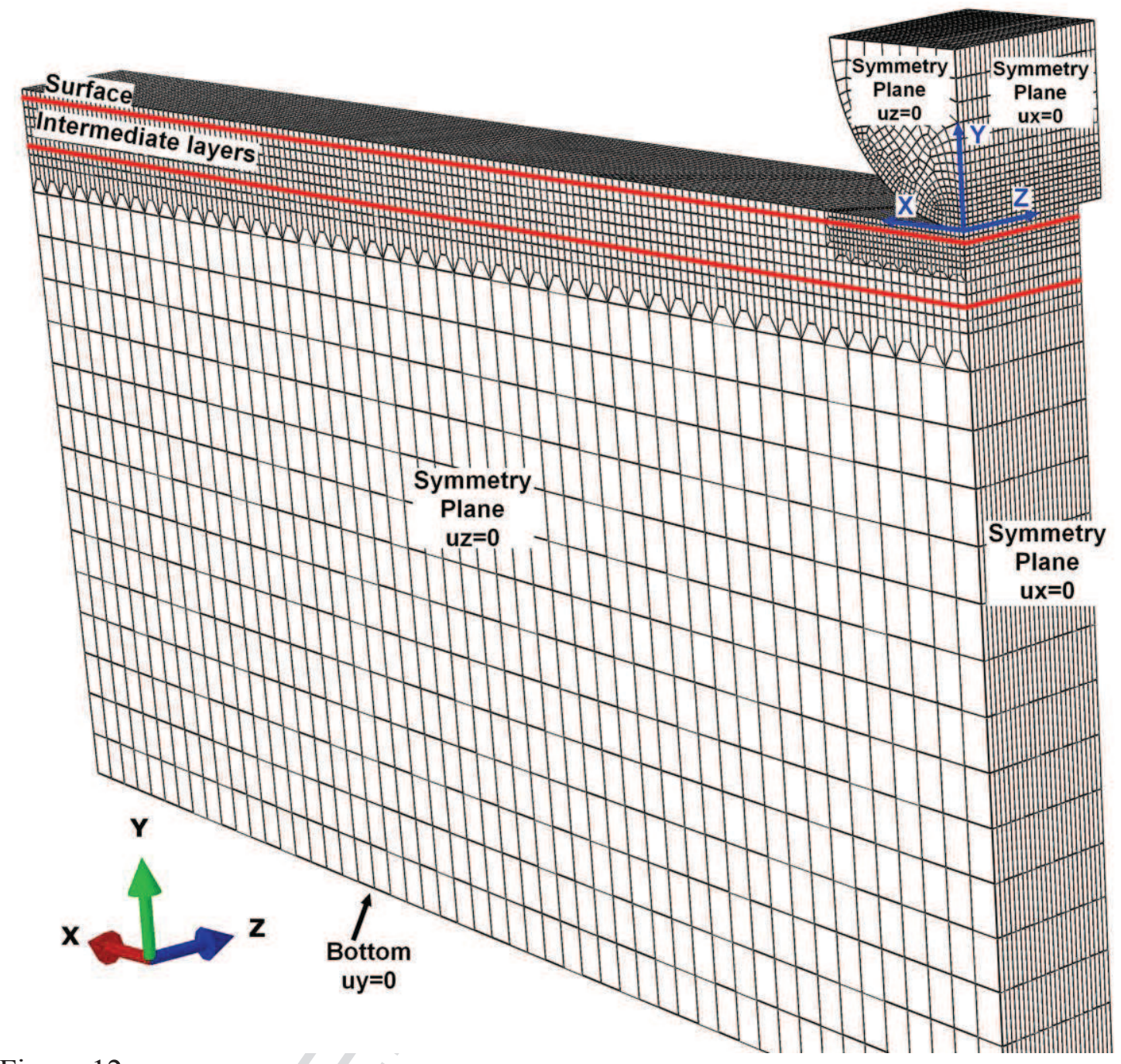

Figure 12 


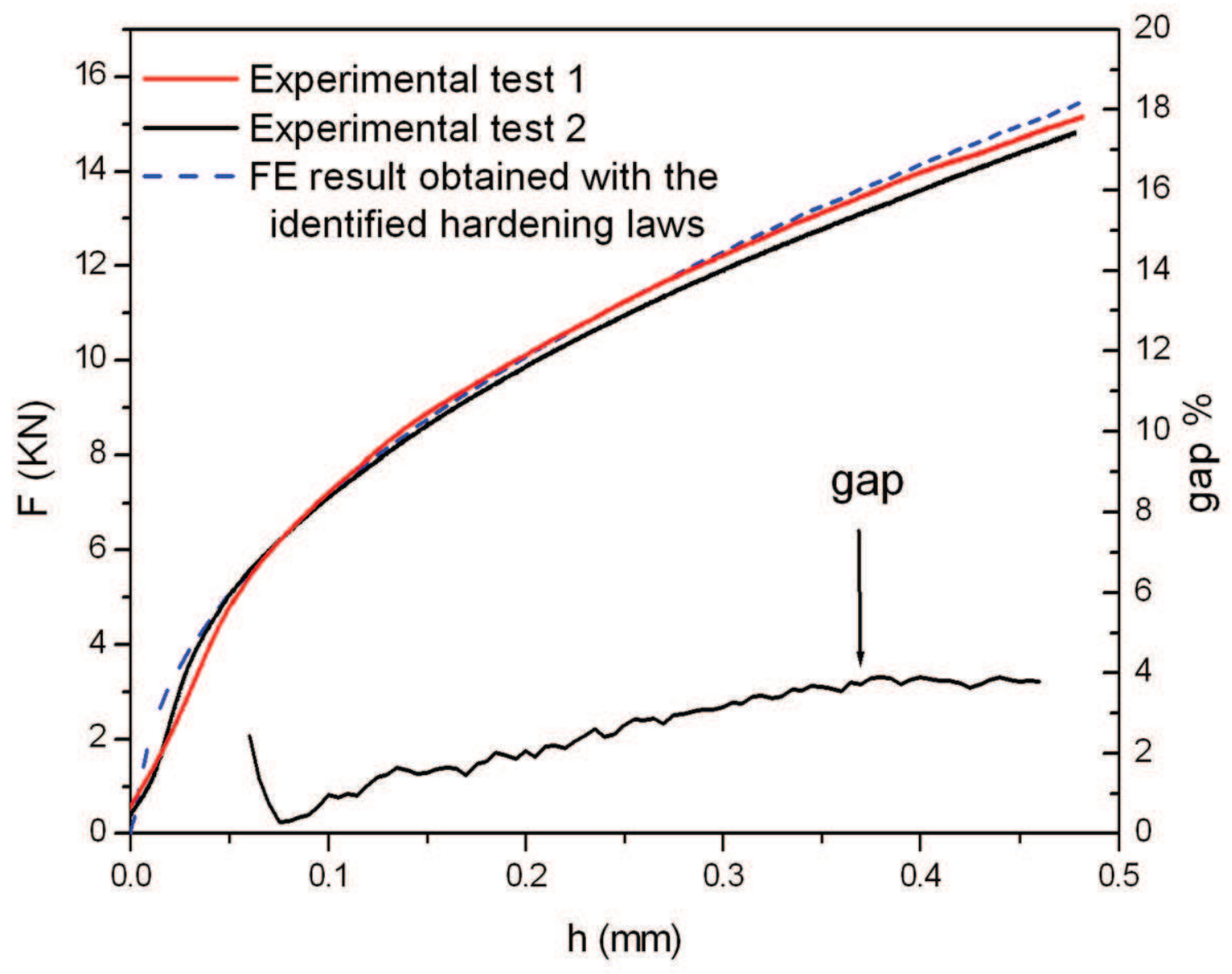

Figure 13 


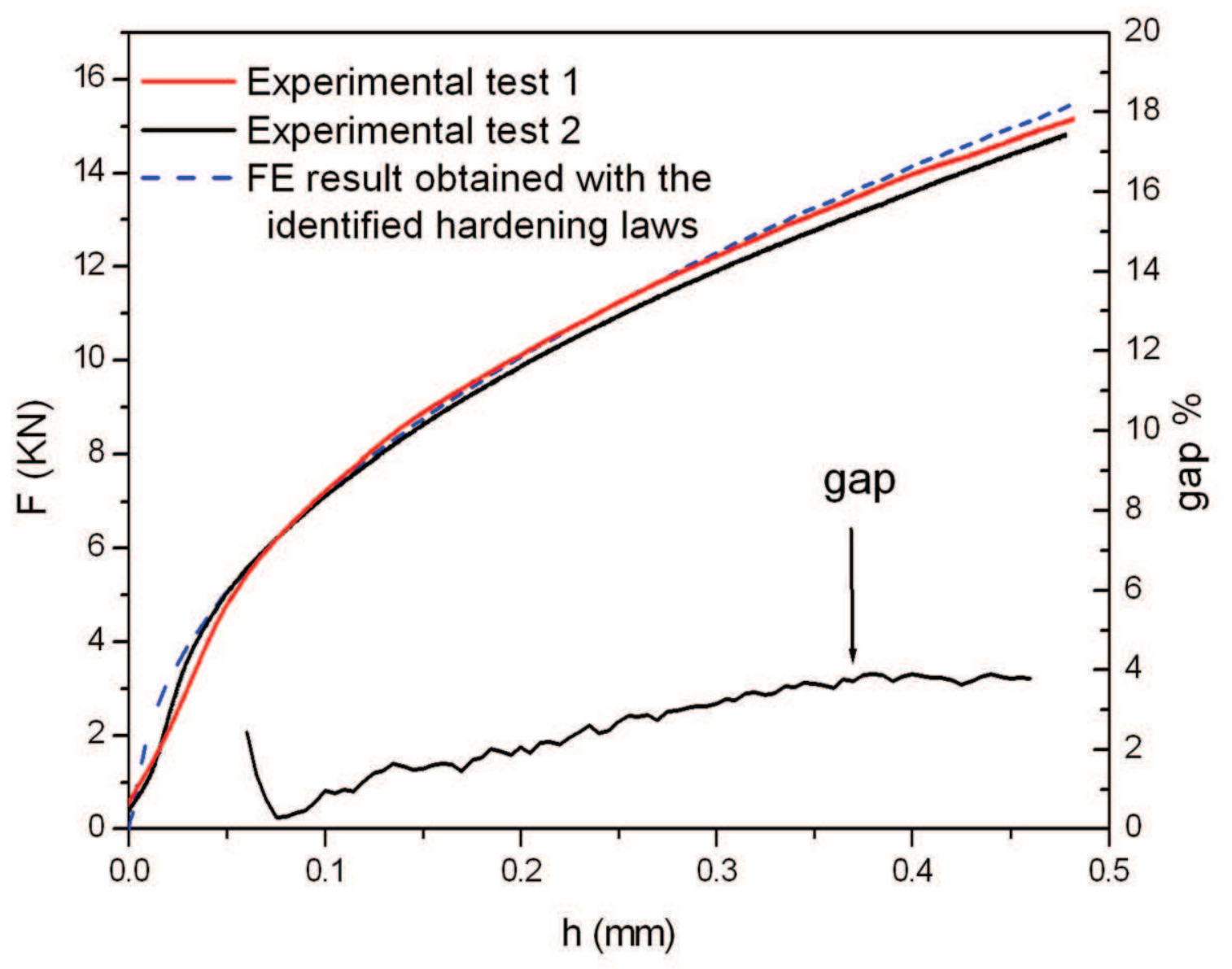

Figure 14 


\section{Figure captions:}

Fig. 1: (a) Hardness profile of the carbonitrided C12 steel obtained from three samples (b) Simplified hardening profile with the depths of the samples used the characterization

Fig. 2: Microstructures of carbonitrided C12 steel at different depths from the surface (a) Surface $z=0 \mathrm{~mm}$, (b) Intermediate layer $z=0.18 \mathrm{~mm}$, (c) Substrate $z=0.5 \mathrm{~mm}$

Fig. 3: Method for the characterization of carbonitrided steels

Fig. 4: The four cases studied to simulate the evolution of the hardening law with depth

Fig. 5: Equivalent plastic strain underneath the indenter of the carbonitrided steel simulated with 32 layers

Fig. 6: Indentation curves of a carbonitrided steel simulated with the four different models and gap between the case of 32 layers and the other cases

Fig. 7: Diagram of the seven tested samples

Fig. 8: Comparison between experimental indentation curves and FE simulation curves obtained for the seven studied samples.

Fig. 9: Identified Hollomon hardening law parameters for the seven layers

Fig. 10: Results of the characterization of the carbonitrided C12 steel:

(a) Identified stress-strain curves for each layer

(b) Variation of stress with depth for two plastic strain values: 0 and 0.1

Fig. 11: Diagram of the instrumented roller indentation test.

Fig. 12: Finite element simulation model of the instrumented roller indentation test.

Fig. 13: Instrumented roller indentation curves obtained from experimental testing and finite elements simulation. 


\section{Tables}

Substrate Substrate +1 Substrate +2 Substrate +3 Substrate +4 Substrate +5 Surface

\begin{tabular}{cccccccc}
\hline \hline$\sigma_{y}(\mathbf{M P a})$ & 315 & 649 & 824 & 1288 & 1438 & 1640 & 1985 \\
$\boldsymbol{n}$ & 0,166 & 0,146 & 0,119 & 0,082 & 0,116 & 0,097 & 0,077
\end{tabular}

Table 1: Mechanical parameters identified for each layer 


\section{Highlights}

A method for the mechanical characterization of carbonitrided steels is proposed.

The variation of the hardening law carbonitrided steels can be considered linear.

The carbonitrided steel can be modelled as a seven layer material.

An instrumented roller indentation test was developed to verify the results.

The verification of the results demonstrates the reliability of the proposed method. 